\title{
Development of airglow temperature photometers with cooled-CCD detectors
}

\author{
K. Shiokawa ${ }^{1}$, Y. Otsuka ${ }^{1}$, S. Suzuki ${ }^{1}$, T. Katoh ${ }^{1}$, Y. Katoh ${ }^{1}$, M. Satoh ${ }^{1}$, T. Ogawa ${ }^{1}$, H. Takahashi ${ }^{2}$, D. Gobbi ${ }^{2}$, \\ T. Nakamura ${ }^{3}$, B. P. Williams ${ }^{4,7}$, C.-Y. She ${ }^{4}$, M. Taguchi ${ }^{5}$, and T. Shimomai ${ }^{6}$ \\ ${ }^{1}$ Solar-Terrestrial Environment Laboratory, Nagoya University, Toyokawa, Japan \\ ${ }^{2}$ Instituto Nacional de Pesquisas Espaciais, INPE, São José dos Campos, SP, Brazil \\ ${ }^{3}$ Research Institute for Sustainable Humanosphere, Kyoto University, Uji, Japan \\ ${ }^{4}$ Department of Physics, Colorado State University, Fort Collins, Colorado, USA \\ ${ }^{5}$ National Institute of Polar Research, Itabashi, Tokyo, Japan \\ ${ }^{6}$ Interdisciplinary Faculty of Science and Engineering, Shimane University, Matsue, Japan \\ ${ }^{7}$ NorthWest Research Associates, Colorado Research Associates division, Boulder, Colorado, USA
}

(Received May 9, 2006; Revised April 7, 2007; Accepted April 7, 2007; Online published June 27, 2007)

\begin{abstract}
We have developed three airglow temperature photometers with cooled-CCD detectors. The photometers measure rotational temperatures using the airglow emissions of $\mathrm{OH}$ and $\mathrm{O}_{2}$ near the mesopause region (altitude: 80-100 km). The photometers also measure six other airglow and auroral lines at wavelengths of 557.7, 630.0, $777.4,589.3,427.8$, and $486.1 \mathrm{~nm}$. The CCD detectors are used to distinguish the emission lines in these airglow bands, similarly to those used by the Spectral Airglow Temperature Imagers (SATI). In this paper, we describe the configuration of the photometers, their calibration, the data processing to extract rotational temperatures and emission intensities from the measured airglow spectra, as well as the initial deployment at Platteville, Colorado $\left(40.2^{\circ} \mathrm{N}, 255.3^{\circ} \mathrm{E}\right)$, when their observations were compared with the concurrent and nearly collocated observations by a sodium lidar. We obtain a good correlation and some systematic difference of temperatures from the photometers and the lidar, and discuss possible causes of the temperature difference.
\end{abstract}

Key words: Airglow temperature photometers, airglow emissions, rotational temperature, cooled CCD, mesopause region.

\section{Introduction}

Mesospheric temperature is an important parameter in the dynamics and chemistry of the middle atmosphere. The temperature can indicate short-term dynamical variations by planetary waves, tides, and gravity waves in the middle atmosphere, as well as long-term cooling of the middle atmosphere associated with the global warming of the troposphere. Sodium lidars and airglow photometers are two major remote-sensing techniques to measure absolute values of the temperatures in the middle atmosphere. The former gives accurate absolute temperatures with their height profiles in the sodium layer at $\sim 80-105 \mathrm{~km}$ (e.g., She et al., 2000). The latter gives temperatures averaged over the airglow emission layers. The airglow photometer is a compact, low-cost instrument and can be easily automated.

The airglow photometers have used the hydroxyl $\mathrm{OHH}\left(v^{\prime}\right.$, $\left.\left.v^{\prime \prime}\right)\right)$ and molecular oxygen $\left(\mathrm{O}_{2} \mathrm{~b}(0,1)\right)$ airglow band emissions to measure the temperatures through rotational lines (e.g., Chamberlain, 1961; Meriwether, 1975; French et al., 2000; Takahashi et al., 2002; Gavrilyeva and Ammosov, 2002; Slanger et al., 2003; Sigernes et al., 2003; Cho et al., 2004; Taori et al., 2005). Figure 1 shows the relative line intensities of the $\mathrm{OH}(6,2)$ Meinel $Q$ - and $P$-branches and the $\mathrm{O}_{2}(0,1)$ Atmospheric band system $\left(b^{1} \Sigma_{g}^{+} \rightarrow X^{3} \Sigma_{g}^{-}\right)$

Copyright (c) The Society of Geomagnetism and Earth, Planetary and Space Sciences (SGEPSS); The Seismological Society of Japan; The Volcanological Society of Japan; The Geodetic Society of Japan; The Japanese Society for Planetary Sciences; TERRAPUB at a temperature of $200 \mathrm{~K}$ (Langhoff et al. (1986) for OH; Krupenie (1972) for $\mathrm{O}_{2}$ ). The relative line intensities vary depending on the temperature of the emitting molecules. It is believed that the $\mathrm{OH}$ rotational level populations are in a thermodynamic equilibrium with the ambient gas at least for the lower rotational levels (Pendleton et al., 1993). The lifetime of the $\mathrm{O}_{2} \mathrm{~b}(v=0)$ state $(>10$ s) seems to be sufficient to reach a thermodynamic equilibrium with the ambient atmosphere. By measuring the intensities at several rotational lines, one can measure the temperature of the atmosphere. The $\mathrm{OH}$ and $\mathrm{O}_{2}$ bands have emission layers near the mesopause region with peaks at $\sim 86 \mathrm{~km}$ and $\sim 94 \mathrm{~km}$, respectively, and thicknesses of $\sim 8-10 \mathrm{~km}$ (e.g., Zhang et al., 1993; Zhang and Shepherd, 1999).

A highly sensitive cooled-CCD camera was originally used as a detector of the airglow photometer named "Mesospheric Oxygen Rotational Temperature Imager (MORTI)" for the measurement of the $\mathrm{O}_{2}$ band (Wiens et al., 1991). The Spectral Airglow Temperature Imager (SATI) was subsequently developed as a revision of MORTI, measuring rotational temperatures of both the $\mathrm{OH}$ and $\mathrm{O}_{2}$ bands (Wiens et al., 1997; Sargoytchev et al., 2004). SATI has been widely introduced in Spain, Japan, and Canada (e.g., Won et al., 2003; López-González et al., 2004; Shiokawa et al., 2004; Cho and Shepherd, 2006).

As described by Sargoytchev et al. (2004), SATI uses a cooled-CCD detector to image airglow lines as concentric circles with spectral scanning in the radial direction and sky 

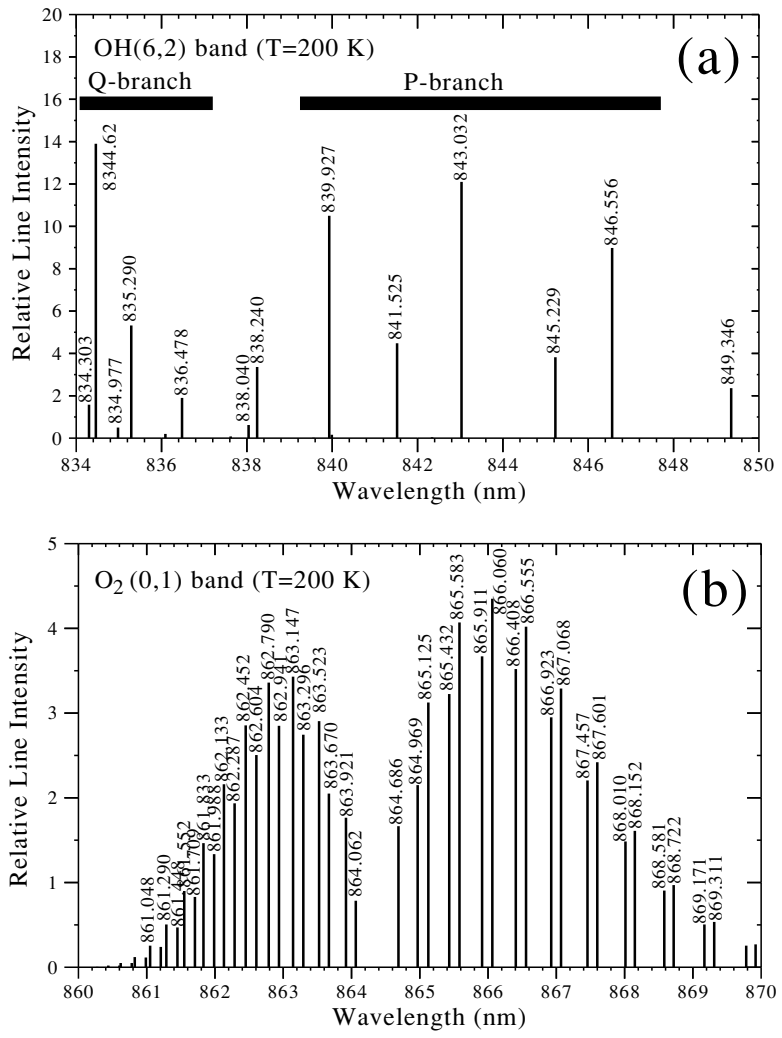

Fig. 1. Relative line intensities of (a) $\mathrm{OH}(6,2)$ band $Q$ - and $P$-branches and (b) $\mathrm{O}_{2}(0,1)$ band at a temperature of $200 \mathrm{~K}$ based on the theoretical transition probabilities by Langhoff et al. (1986) $(\mathrm{OH})$ and Krupenie (1972) $\left(\mathrm{O}_{2}\right)$.

azimuth in the azimuthal direction. It has an annular field of view in the sky, with a radius in zenith angles of $26.32^{\circ}-$ $33.55^{\circ}$. The temperature and intensity of airglow emission are obtained for 12 azimuthal directions. The narrow-band filters of SATI work as a Fabry-Perot etalon to make the spectral scanning in the radial direction on the CCD. The rotational temperatures can be determined with a standard deviation of $1.7 \mathrm{~K}$ for an exposure time of $2 \mathrm{~min}$.

In this paper, we report the details of three airglow temperature photometers with cooled-CCD detectors. The photometers have a basically similar optical configuration to that of SATI. However, three revisions have been made. One is that the new photometer measures $\mathrm{OH}(6,2) P$ branches instead of $Q$-branches of SATI. The $\mathrm{OH}(6,2) P$ branches have been widely used in previous photometers and their transition probabilities have been well investigated (e.g., Greet et al., 1998; French et al., 2000 and references therein). SATI used $Q$-branches mainly because it is easier to fit the $Q$-branch spectra into a limited CCD size, since the spectral width of the $Q$-branch is narrower than the $P$ branch, as shown in Fig. 1. However, the rotational temperature measurement through $\mathrm{OH}(6,2) Q$-branches contains possible systematic errors, irrespective of the specific choice of the Einstein coefficients, as pointed out by Pendleton and Taylor (2002).

The second revision is that the new photometer has a small aperture $(28.7 \mathrm{~mm} \phi)$ at the top of the optics without a conical mirror. The conical mirror introduced by MORTI and SATI makes it possible to measure the horizontal prop-

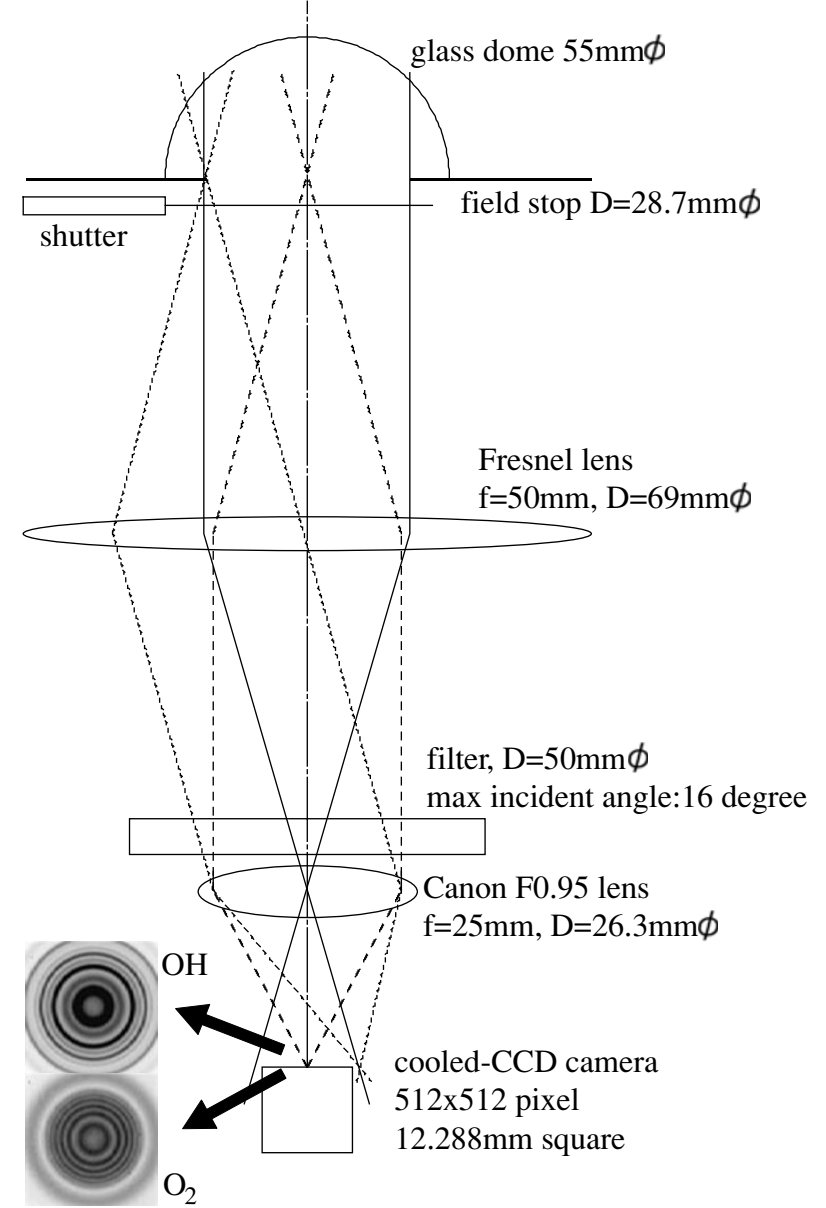

Fig. 2. Schematic illustration of the optics of the airglow temperature photometer.

agation of gravity waves by setting the field of view as a circular shape in the sky with zenith angles of $26.32^{\circ}-$ $33.55^{\circ}$. However, because of this conical mirror and associated complicated structure at the top of the optics, it was difficult to make a spectral calibration through the entire optics of SATI. The simple optics with a small aperture of the new photometer allows us to fully calibrate the spectral response of the optics.

The third revision is that the three new photometers have two identical filters (six filters in total) for both $\mathrm{OH}$ and $\mathrm{O}_{2}$ bands to facilitate cross calibrations between the filters and to monitor for possible degradation of a specific filter during long-term measurements.

\section{Optical Configuration}

Figure 2 shows the optical system of the airglow temperature photometer. We use a thinned and back-illuminated cooled CCD with $512 \times 512$ pixels made by the Hamamatsu Photonics (model: C4880-30-24A). The CCD has a quantum efficiency of more than $90 \%$ in the visible wavelengths and more than $60 \%$ at $850 \mathrm{~nm}$. The size of one pixel is $24 \mu \mathrm{m}$, giving a CCD size of $12.288 \times 12.288 \mathrm{~mm}$. In order to reduce the relative read-out noise, we use $4 \times 4$ onchip binning of the CCD. Thus, the CCD output image is 64 $\times 64$ large pixels. The CCD surface is cooled down to less than $-60^{\circ} \mathrm{C}$ using a thermoelectric cooler. The dark noise is 
Table 1. Filter specifications of the airglow temperature photometers.

\begin{tabular}{ccccccc}
\hline Channel & $\begin{array}{c}\text { Center } \\
\text { wavelength } \\
(\mathrm{nm})\end{array}$ & $\begin{array}{c}\text { Band } \\
\text { width } \\
(\mathrm{nm})\end{array}$ & $\begin{array}{c}\text { Peak } \\
\text { transmission } \\
(\%)\end{array}$ & $\begin{array}{c}\text { Refractive } \\
\text { index }\end{array}$ & $\begin{array}{c}\text { Exposure } \\
\text { time } \\
(\mathrm{s})\end{array}$ & Species \\
\hline 1 & 847.2 & 0.7 & $>45$ & 1.45 & 60 & $\mathrm{OH}(6,2) \mathrm{P}_{1}(2,3,4)$ \\
2 & 847.2 & 0.7 & $>45$ & 1.45 & 60 & $\mathrm{OH}(6,2) \mathrm{P}_{1}(2,3,4)$ \\
3 & 867.7 & 0.25 & $>35$ & 2.05 & 60 & $\mathrm{O}_{2} \mathrm{~b}(0,1)$ \\
4 & 867.7 & 0.25 & $>35$ & 2.05 & 60 & $\mathrm{O} 2 \mathrm{~b}(0,1)$ \\
5 & 558.5 & 1.0 & $>50$ & 2.05 & 10 & $\mathrm{OI}(557.7 \mathrm{~nm})$ \\
6 & 630.9 & 1.0 & $>55$ & 2.05 & 10 & $\mathrm{OI}(630.0 \mathrm{~nm})$ \\
7 & 778.5 & 0.5 & $>60$ & 2.05 & 20 & $\mathrm{OI}(777.4 \mathrm{~nm})$ \\
8 & 590.1 & 0.5 & $>50$ & 2.05 & 10 & $\mathrm{Na}(589.3 \mathrm{~nm})$ \\
9 & 428.4 & 1.0 & $>25$ & 1.45 & 60 & $\mathrm{~N}_{2}^{+}(1 \mathrm{NG}, 427.8 \mathrm{~nm})$ \\
10 & 486.8 & 1.0 & $>45$ & 2.05 & 60 & $\mathrm{H} \beta(486.1 \mathrm{~nm})$ \\
$11^{*}$ & 878.3 & 0.3 & $>50$ & 2.05 & 60 & $\mathrm{OH}(7,3) \mathrm{R}_{1}(1,2,3)$ \\
\hline
\end{tabular}

*Photometer 1 only.

less than 1 electrons/pixel/s, while the read-out noise (rootmean-square) is $\sim 10$ electrons.

The basic interference optics consist of the $50-\mathrm{mm} \phi$ filter and the Canon F0.95 lens. The light rays that pass through the narrowband interference filter with incident angles of $0^{\circ}$ and $19.1^{\circ}\left(=\tan ^{-1}(12.288 \mathrm{~mm} \times \sqrt{2} / 2 / 25 \mathrm{~mm})\right)$ are focused on the center and the four corners of the CCD, respectively. The center wavelength of the narrowband interference filter shifts toward a shorter wavelength with an increasing angle of the incident light. The wavelength shift is given as,

$$
\lambda=\lambda_{0}\left(1-\frac{\mu_{0}^{2}}{\mu^{2}} \sin ^{2} \theta\right)^{1 / 2},
$$

where $\lambda, \lambda_{0}, \theta, \mu_{0}$, and $\mu$ are the shifted wavelength, original wavelength, incident angle, and refractive indices of the external medium ( $\mu_{0}=1.0$ for air) and the filter, respectively. Typical values of $\mu$ are 1.45 or 2.05 for interference filters. In the case of $\lambda_{0}=840 \mathrm{~nm}$, the incident angle of $10^{\circ}$ gives wavelength shifts of 3 and $6 \mathrm{~nm}$ for $\mu=2.05$ and 1.45 , respectively. For $\mathrm{OH}$ and $\mathrm{O}_{2}$ airglow bands, several emission lines exist in the range of this wavelength shift, as shown in Fig. 1. For the $\mathrm{OH}$ measurement, we took the lower refractive index of 1.45 for the filter, so the wide wavelength range of $\mathrm{OH}(6,2) \mathrm{P}(2), \mathrm{P}(3)$, and $\mathrm{P}(4)$ lines can be put into a CCD image. As a result, the output image on the CCD shows concentric fringes, each of which corresponds to an emission line, as shown in Fig. 2. By taking the intensity ratio of these fringes, one can measure the rotational temperature of the emitting molecules. By this method, the CCD gives the advantage of two-dimensional imaging in the wavelength range. The MORTI and SATI put a conical mirror at the location of the top field stop to obtain azimuthal information of the sky.

The Fresnel lens (focal length: $50 \mathrm{~mm}$, diameter: $69 \mathrm{~mm}$ ) is introduced to smear out the structures in the sky, such as stars and airglow structures by gravity waves. If the Fresnel lens is removed, these sky structures would be projected on the CCD together with the interference fringes, thereby preventing accurate measurement of the line intensities. Using the Fresnel lens, the sky is completely defocused and the image at the 28.7-mm $\phi$ field stop at the top of the optics is projected onto the CCD. The incident light passes through the filter with a maximum angle of $16^{\circ}$. This angle is determined by the field stop at the top of the optics $\left(16^{\circ}\right.$ $\left.=\tan ^{-1}(28.7 \mathrm{~mm} / 2 / 50 \mathrm{~mm})\right)$ and corresponds to the field of view of the photometer. Thus, the photometer measures rotational temperatures and airglow emission rates averaged over a zenith area with zenith angles less than $16^{\circ}$. These configurations are basically identical for the three photometers, although the shutter of Photometer 1 is given by a wheel above the Fresnel lens.

The $50-\mathrm{mm} \phi$ interference filter is on a wheel, which can mount a maximum 12 filters in it. Table 1 lists the specifications of the narrowband interference filters used for the three photometers. The three photometers have ten filters with identical specifications. For the rotational temperature measurements of $\mathrm{OH}$ and $\mathrm{O}_{2}$, two filters with identical specifications are used in each photometer in order to make a cross calibration and to monitor possible degradation of the filters during a long-term measurement. Photometer 1 has an extra filter to measure the $\mathrm{OH}(7,3) R$-branches for an experimental purpose. The filters for 557.7, 630.0, 777.4, and $589.3 \mathrm{~nm}$ are for the measurement of mid- and low-latitude airglow emissions. The filters of $427.8 \mathrm{~nm}\left(\mathrm{~N}_{2}^{+}(1 \mathrm{NG}, 0-1)\right)$ and $486.1 \mathrm{~nm}(\mathrm{H} \beta)$ are for atmospheric emissions associated with energetic particle precipitation from the terrestrial ring current (e.g., Tinsley et al., 1984). The narrowband filters of channels 3, 4, and 11 are made with two cavities, while other filters are made with three cavities.

The exposure time of each channel is also listed in Table 1. The filter sequence can be set by a program. Usually we take exposures of channels 1-8 sequentially for five times and then take exposures of channels 9-11 and dark images. Such a sequence gives time resolutions of $5.5 \mathrm{~min}$ for channels 1-8 and 32.5 min for channels 9-11.

\section{Calibration}

The output count $N_{i}$ at the $i$ th pixel of the photometer is given as

$$
N_{i}=a_{i} t \int I(\lambda) T_{i}(\lambda) d \lambda+N_{d},
$$

where $a_{i}, t, \lambda, I(\lambda), T_{i}(\lambda)$, and $N_{d}$ are absolute sensitivity, integration time, wavelength, intensity of the incident light (in Rayleigh/nm), spectral transmission, and dark count, respectively. In order to calculate rotational temperature and 

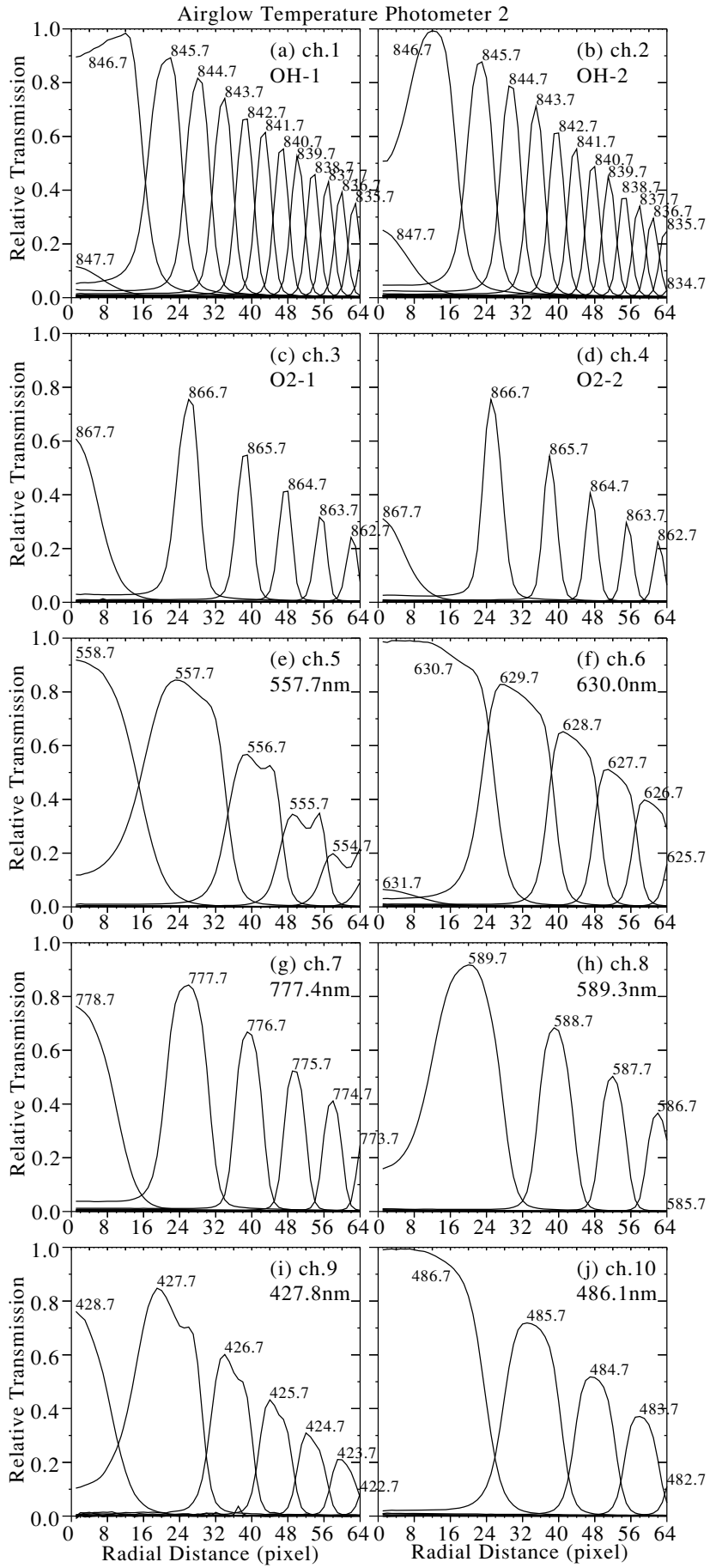

Fig. 3. Relative transmissions for 10 filters of Photometer 2 measured by using a monochromatic light source from an 8-inch integrating sphere. The transmission images are averaged over the azimuthal direction. The abscissa is the radial distance from the center of the interference fringes. The numbers near the peak of the curves indicate wavelengths of incident light in unit of $\mathrm{nm}$.

intensity of airglow from the fringe image of the photometer, we need to obtain the two parameters, spectral transmission $T_{i}(\lambda)$ and absolute sensitivity $a_{i}$, through the calibration. Assuming an azimuthal symmetry, we integrate the fringe images in the azimuthal direction. Thus, the pixel number $i$ indicates radial distance from the center of the fringe. The dark count $N_{d}$ can be obtained by taking an image with the shutter closed.
To obtain the spectral transmission function $T_{i}(\lambda)$, we used a monochromatic light with a wavelength width of $0.1 \mathrm{~nm}$ generated by a grating spectrometer of the National Institute of Polar Research (NIPR). Because the CCD is focused to the 28.7-mm $\phi$ hole on the field stop at the top of the photometer (Fig. 2), we need to illuminate the hole uniformly by the monochromatic light. For that purpose we introduced an integrating sphere with a diameter of 8 inches. The monochromatic light from the grating spectrometer is put into the integrating sphere. The sphere has a 2 -inch $(50.8 \mathrm{~mm} \phi)$ window at the $90^{\circ}$ location from the light input. The window is set to the $28.7-\mathrm{mm} \phi$ hole of the photometer to put the monochromatic light into the photometer uniformly. This process can be done because of the small aperture of the photometer. For SATI and MORTI, this calibration was difficult because of their large apertures and the conical mirror on the top of the optics.

For the spectral calibration, the output count $N_{i, k}$ for the monochromatic light input with a wavelength of $\lambda_{k}$ is expressed as,

$$
N_{i, k}=a_{i} t I\left(\lambda_{k}\right) T_{i}\left(\lambda_{k}\right) \Delta \lambda_{k}+N_{d},
$$

where $\Delta \lambda_{k}=0.1 \mathrm{~nm}$ for the present case. From Eq. (3), the spectral transmission function $T_{i}\left(\lambda_{k}\right)$ is obtained as,

$$
T_{i}\left(\lambda_{k}\right)=\frac{N_{i, k}-N_{d}}{a_{i} t I\left(\lambda_{k}\right) \Delta \lambda_{k}} .
$$

Because we do not know $a_{i}$ and the absolute intensity $I\left(\lambda_{k}\right)$ of the monochromatic light, the transmission function can be obtained as relative values normalized by a maximum transmission at $i_{0}$ and $k_{0}$. We consider the dependence of the spectrometer irradiance $I\left(\lambda_{k}\right)$ on wavelength $\lambda_{k}$, which is basically the variation of the irradiance of the tungsten lamp.

Figure 3 indicates the spectral transmission $T_{i}\left(\lambda_{k}\right)$ obtained by the above calibration for the ten filters of Photometer 2 as a function of $\lambda_{k}$ and radial distance $i$ from the center of the fringes. These curves are normalized by the maximum transmission of all the radial distances $i$ and $\lambda_{k}$. The $T_{i}\left(\lambda_{k}\right)$ curves are indicated every $1 \mathrm{~nm}$ in this figure, while the calibration is done for every $0.1 \mathrm{~nm}$. As the wavelength decreases, the transmission peak shifts outward as expected from Eq. (1). The width of the transmission becomes narrower for shorter wavelengths (larger incident angles).

The curves in channels 5 and 9 are slightly distorted at shorter wavelengths. This distortion can happen with threecavity filters, which have a square-shape transmission for $0^{\circ}$ incident angle. These distortions do not affect the measurements, since we fit these transmission functions directly to the observed airglow spectra to obtain the airglow emission rate.

To obtain the absolute sensitivity $a_{i}$ in Eq. (2), we used a panchromatic (white) light source with a known intensity, provided by an integrating sphere with a diameter of $2 \mathrm{~m}$ at NIPR. The 28.7-mm $\phi$ hole on the field stop at the top of the photometer is illuminated uniformly by this panchromatic light source. For the absolute-sensitivity calibration, the output count $N_{i}$ from a known light source $I(\lambda)(\mathrm{R} / \mathrm{nm})$ is 


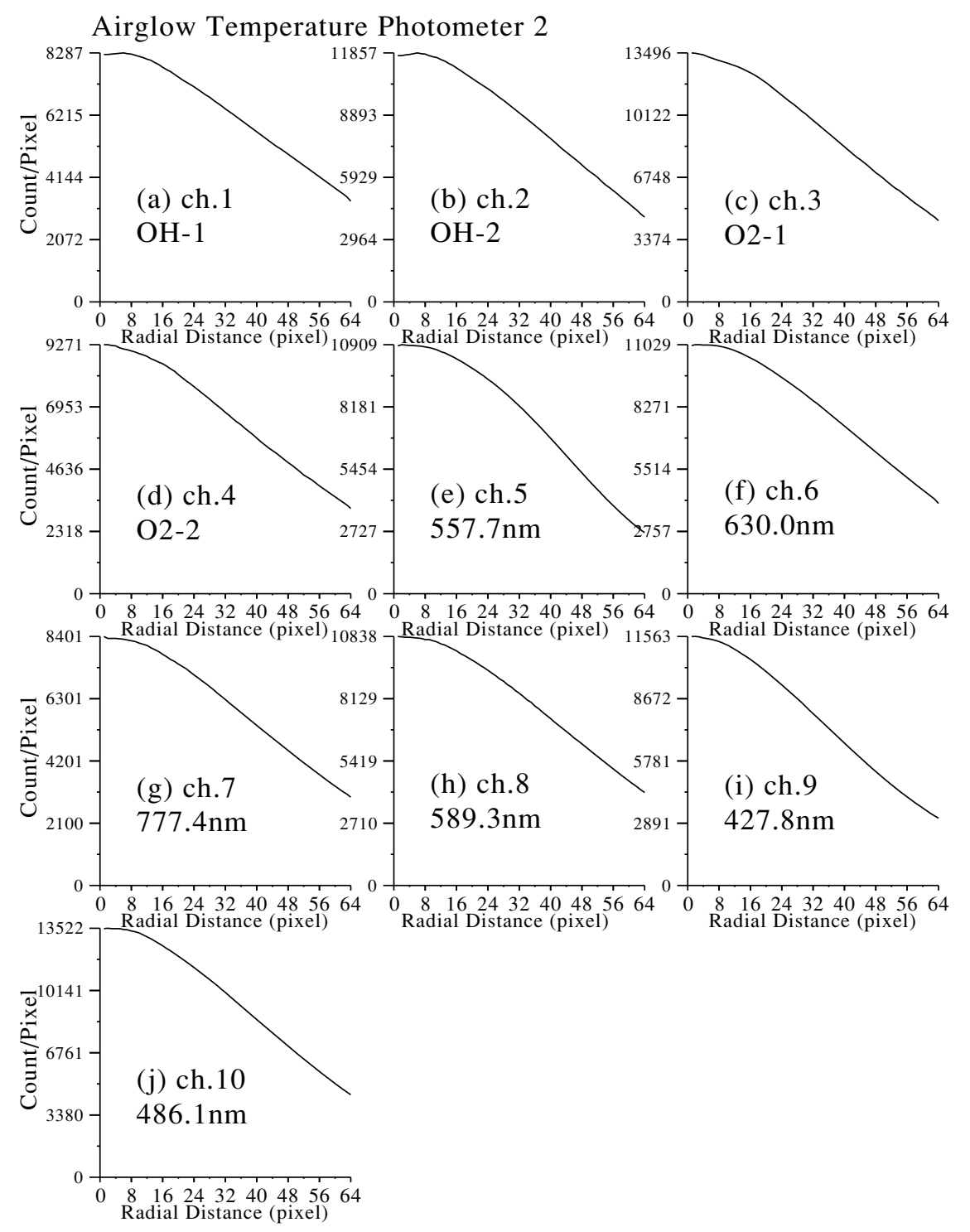

Fig. 4. Azimuthally-averaged distribution of output count per CCD pixel obtained by putting the panchromatic uniform light from the 2-m integrating sphere to Photometer 2. The images are averaged over the azimuthal direction, similarly to that of Fig. 3.

given by writing Eq. (2) in summation form as,

$$
N_{i}=a_{i} t \sum_{k} I\left(\lambda_{k}\right) T_{i}\left(\lambda_{k}\right) \Delta \lambda_{k}+N_{d}
$$

Thus, the absolute sensitivity $a_{i}$ can be obtained as

$$
a_{i}=\frac{N_{i}-N_{d}}{t \sum_{k} I\left(\lambda_{k}\right) T_{i}\left(\lambda_{k}\right) \Delta \lambda_{k}} .
$$

The transmission function $T_{i}\left(\lambda_{k}\right)$ (Eq. (4)) normalized by the maximum transmission can be used in Eq. (6) to calculate $a_{i}$.

Figure 4 shows the azimuthally-averaged distribution of output counts per pixel obtained by putting the panchromatic uniform light from the 2-m integrating sphere into Photometer 2. The dark counts $N_{d}$ have been subtracted from these data. There is a significant limb-darkening from the center to the edge of the images for all channels. The uniform light at the top of the optics becomes significantly non-uniform with counts less than $40 \%$ at the edge of the image compared to that at the center. This limb-darkening is mainly caused by the Canon F0.95 lens, and it may cause a systematic error of the output rotational temperatures if the optics are not properly calibrated.

Figure 5 indicates the absolute sensitivities $a_{i}$ (count/R/s) for ten channels of Photometer 2, calculated by Eq. (6) using the data in Figs. 3 and 4. The sensitivity ranges from 0.5 to 2.5 count $/ \mathrm{R} / \mathrm{s}$, giving an estimate that a $60-\mathrm{s}$ exposure of $100 \mathrm{R}$ airglow would produce 3,000-15,000 counts. The sensitivity is lower in channels 3 and 4 because the narrower bandwidth of the filter $(0.25 \mathrm{~nm})$ results in lower transmission.

\section{Synthetic Spectra}

In the actual observation of the sky, the airglow emission rate is proportional to the peak counts of the fringes. However, if several emission lines with a small wavelength difference, like those in Fig. 1, are included in one fringe image, they contaminate each other, because the spectral transmission functions have certain widths, as shown in Fig. 3. 


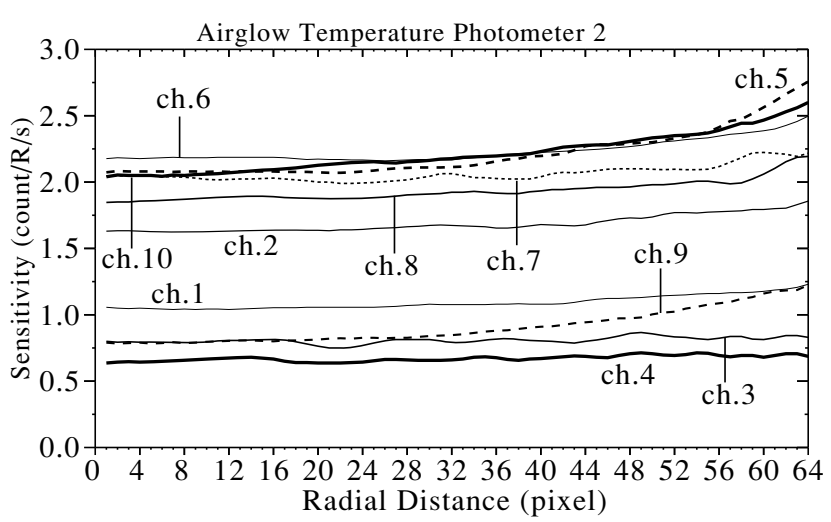

Fig. 5. Sensitivity in unit of count/Rayleigh/s for each channel and each radial distance from the center of the images.

In order to take this spectral contamination into account, we need to fit synthetic spectra to the observed fringes. The synthetic spectra are defined as follows.

If there are several emission lines with intensities of $I_{1}$, $I_{2}, \ldots, I_{n}$ (Rayleigh) at wavelengths of $\lambda_{1}, \lambda_{2}, \ldots, \lambda_{n}$, the output count $N_{i}$ (count/pixel) at the $i$ th radial distance of the photometer is given from Eq. (2) as

$$
\begin{aligned}
N_{i}= & a_{i} t\left(I_{1} T_{i}\left(\lambda_{1}\right)+I_{2} T_{i}\left(\lambda_{2}\right)+\ldots\right. \\
& \left.+I_{n} T_{i}\left(\lambda_{n}\right)+I_{b} \sum_{k} T_{i}\left(\lambda_{k}\right) \Delta \lambda_{k}\right)+N_{d},
\end{aligned}
$$

where $I_{b}(\mathrm{R} / \mathrm{nm})$ is the intensity of background continuum emission from the sky. Equation (7) can be rewritten as

$$
y_{i}=t\left(S_{i} I_{r}+B_{i} I_{b}\right),
$$

where

$$
\begin{gathered}
y_{i}=N_{i}-N_{d} \\
S_{i}(T)=a_{i}\left(\frac{I_{1}}{I_{r}} T_{i}\left(\lambda_{1}\right)+\frac{I_{2}}{I_{r}} T_{i}\left(\lambda_{2}\right)+\ldots+\frac{I_{n}}{I_{r}} T_{i}\left(\lambda_{n}\right)\right) \\
B_{i}=a_{i} \sum_{k} T_{i}\left(\lambda_{k}\right) \Delta \lambda_{k}
\end{gathered}
$$

$S_{i}(T)($ count $/ \mathrm{R} / \mathrm{s})$ is the synthetic spectra, which can be determined on the basis of the calibrations described in the previous section. $S_{i}(T)$ depends on the temperature $T(\mathrm{~K})$ of the atmosphere because the relative intensities of rotational airglow bands $I_{1} / I_{r}, I_{2} / I_{r}, \ldots, I_{n} / I_{r}$ are theoretically determined for each temperature from the transition probabilities, as shown in Fig. 1. The reference line of the $\mathrm{OH}(6,2), \mathrm{OH}(7,3)$, and $\mathrm{O}_{2}(0,1)$ bands are taken at wavelengths of $846.5555,877.8271$, and $866.0595 \mathrm{~nm}$, respectively. In the present study, the $\mathrm{OH}(6,2)$-band line intensities were calculated using the molecular constants given by Coxon and Foster (1982) with the Einstein transition probability given by Langhoff et al. (1986). For the calculation of the $\mathrm{O}_{2}(0,1)$ band spectrum, we followed the calculation form given by Meinel (1950) with the molecular constants given by Krupenie (1972). The synthetic spectra for the background continuum emission $B_{i}$ (count $\mathrm{nm} / \mathrm{R} / \mathrm{s}$ ) can be also determined from the calibrations.
For each atmospheric temperature, we fit the linear relation of Eq. (8) to the observed airglow spectra for the parameters of $I_{r}$ and $I_{b}$. The fitting is done by a least-square method to minimize the square of the residuals $\chi^{2}$, which is given as

$$
\chi^{2}=\sum_{i} \frac{1}{\sigma_{i}^{2}}\left(y_{i}-t S_{i} I_{r}-t B_{i} I_{b}\right)^{2},
$$

where $\sigma_{i}^{2}$ is the square of the random error of the output count $N_{i}$ and $N_{d}$ and is basically given by the addition of these counts, assuming that they follow the Poisson distribution. The read-out noise of the CCD is usually larger than the random noise from the dark count and should be also taken into account as an error of $N_{i}$. For the error of $N_{i}$, we need to consider the total count obtained by the integration to the azimuthal direction. Namely, $\sigma_{i}^{2}$ from $N_{i}$ is given by $\sigma_{i}^{2}=N_{i} / m_{i}$, where $m_{i}$ is the number of pixels averaged in the azimuthal direction. By this fitting, we obtain the $I_{r}$ and $I_{b}$ that make $\chi^{2}$ minimum for each temperature. This procedure is repeated for all the temperatures from $100 \mathrm{~K}$ to $300 \mathrm{~K}$ every $1 \mathrm{~K}$, and finally we obtain the three parameters $T(\mathrm{~K}), I_{r}(\mathrm{R})$, and $I_{b}(\mathrm{R} / \mathrm{nm})$ that minimize the residual $\chi^{2}$. For airglow line emissions without temperature variations (channels 5-10), we simply fit Eq. (8) to the observed spectra to obtain $I_{r}$ and $I_{b}$.

Figure 6 indicates synthetic spectra $S_{i}$ (thick solid curves counts/R/s) for airglow emissions and synthetic spectra $B_{i}$ (thick dashed curves in count $\mathrm{nm} / \mathrm{R} / \mathrm{s}$ ) for background continuum emissions for Photometer 2. The thin solid curves for banded emissions in Figs. 6(a)-6(d) and 6(h) indicate the contribution from individual emission lines. The synthetic spectra $S_{i}$ are the summation of the contributions from these lines. For $\mathrm{OH}$ and $\mathrm{O}_{2}$ band emissions, the neighboring lines contaminate each other. Thus, it is not appropriate to take just a peak intensity of each fringe to estimate the line intensity, which is the reason why we use the fitting of the synthetic spectra to the observed fringes to estimate the line intensities correctly. The sodium D-line emission in Fig. 6(h) has two lines at 588.9951 and $589.5924 \mathrm{~nm}$, respectively.

\section{Data Processing}

Using the three photometers, we made a test measurement of the airglow at Platteville, Colorado $\left(40.2^{\circ} \mathrm{N}\right.$, $255.3^{\circ} \mathrm{E}$ ) from September 23 to November 7, 2003. Figure 7 shows examples of the airglow fringe images obtained by Photometer 2 at Platteville on September 25, 2003. A fringe image of $\mathrm{OH}(7,3) R$-branches obtained by Photometer 1 is also shown. As described in the previous sections, concentric fringes are obtained for each filter, corresponding to individual airglow lines. From these fringe images, we took the following four data processing steps to calculate rotational temperatures and airglow emission rates.

(1) Cosmic ray removal: The CCD-detector has white spots in the image due to the incidence of cosmic rays. We identify the white spots by checking pixels in which count differences with neighboring pixels exceed a certain threshold and then replace the count of the cosmic-ray pixels by that of the neighboring pixels. 


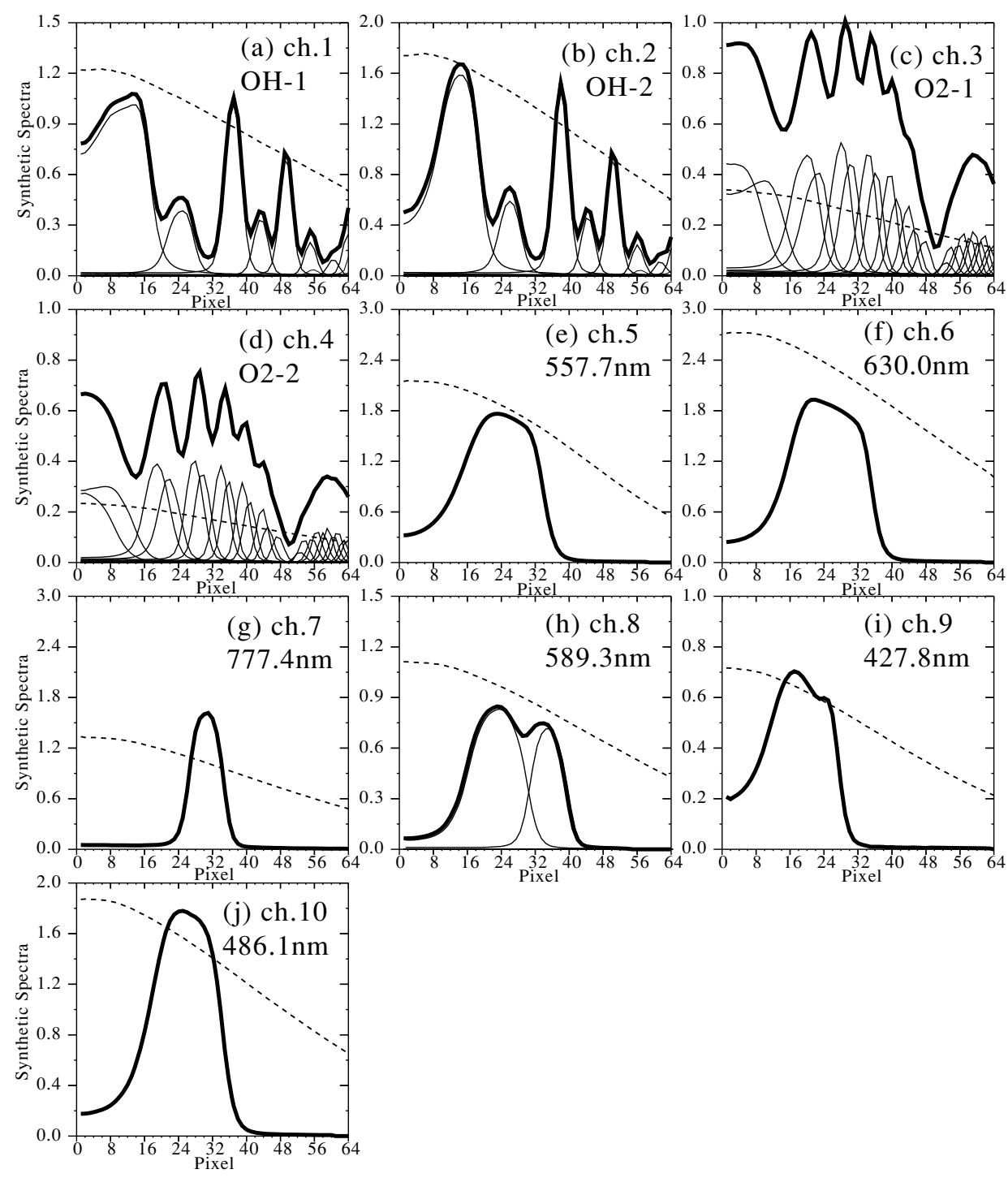

Fig. 6. Synthetic spectra $S_{i}$ (thick solid curves, in unit of count/R/s) for airglow emissions and synthetic spectra $B_{i}$ (dashed curves, in unit of count $\mathrm{nm} / \mathrm{R} / \mathrm{s}$ ) for background continuum emissions for Photometer 2 . The synthetic spectra for $\mathrm{OH}$ and $\mathrm{O}_{2}$ bands are obtained for a temperature of $200 \mathrm{~K}$. The thin solid curves indicate contribution from each airglow line in the banded emission.

(2) Dark count subtraction: The dark images of the CCD, which are necessary to determine the dark counts $N_{d}$, are taken every $32.5 \mathrm{~min}$ by closing the shutter with the same exposure times as those of the airglow images.

(3) Fringe center determination: To make azimuthal integrations of the concentric fringes, we need to determine the center of the fringes. We first take 12 representative images, sampled by an equal interval from one night of observations. We then make an average image of these $12 \mathrm{im}-$ ages. The fringe center is determined for this average image as the location where the peak height of the azimuthallyintegrated fringes becomes maximum. In other words, if the tentative center is not at the same position as the fringe center, the azimuthal integration would cause reduction of the peak height. We make this fringe-center search for every 0.2 pixels and obtain $(x, y)$ coordinates where the azimuthally-integrated fringe peak becomes maximum. A similar method has been adopted by SATI. We also tried to determine the fringe center by fitting a Gaussian function to the horizontal and vertical cross sections of the fringe im- ages. However, the former method gives a more stable and reliable center location.

(4) Filter temperature drift: In the initial analysis of the photometer data, we found that the peak locations of the fringes are slightly different between the synthetic spectra and the observed spectra. This is because the transmission function $T_{i}\left(\lambda_{k}\right)$ drifts with changing temperature of the filter. The drift of the center wavelength of a bandpass filter is typically $\sim 0.02 \mathrm{~nm} /{ }^{\circ} \mathrm{C}$ due to variations in the filter temperature. The photometer has a sheet heater just below the filter wheel that attempts to keep the filter temperature at $35^{\circ} \mathrm{C}$. However, since we cannot put the heater directly on the filter, the filter temperature varies slightly according to changes in the outside temperature. Because we fully calibrate the wavelength dependences of the transmission function as described in Section 3, we can calculate synthetic spectra for the cases when the center wavelength of the filter is shifted by the filter temperature variation. Using a linear interpolation, we calculate synthetic spectra for wavelength shifts of every $0.01 \mathrm{~nm}$ for a range of $\pm 0.4 \mathrm{~nm}$ from the cal- 


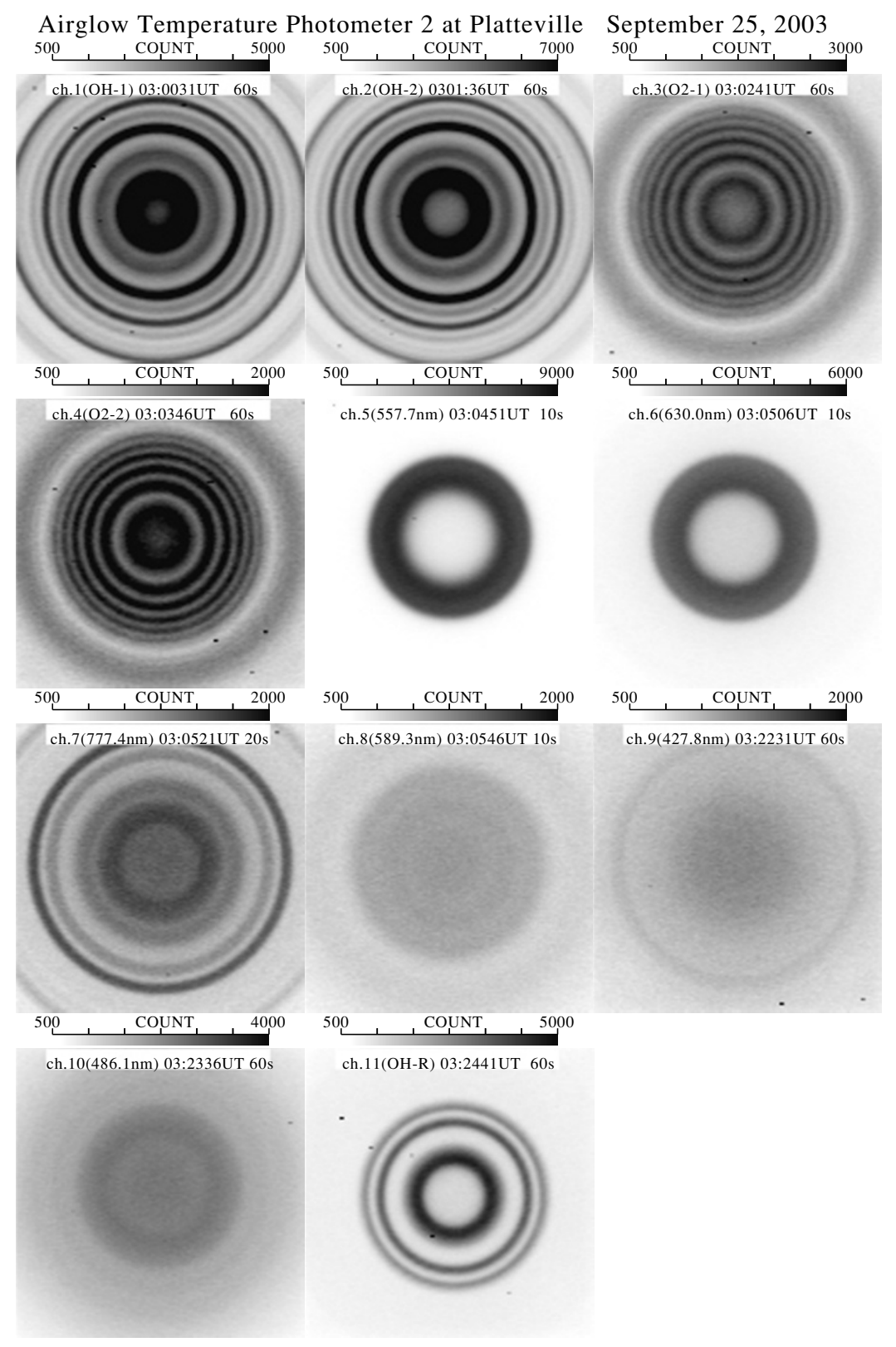

Fig. 7. Examples of the interference fringes for ten filters (ch.1-10) of Photometer 2 and 1 filter (ch.11, OH-R) of Photometer 1. These fringes were obtained at Platteville, Colorado, on September 25, 2003. The channel number, start time of the exposure, and exposure time are indicated at the top of each panel.

ibration data. We fit these synthetic spectra to the observed spectra using Eq. (8) and obtain a best-fit wavelength shift. For $\mathrm{OH}$ and $\mathrm{O}_{2}$ spectra, we assume a rotational temperature of $200 \mathrm{~K}$ to obtain the best-fit synthetic spectra.

After these four data processing steps, we fit the synthetic spectra to the observed spectra using Eq. (8) to obtain the rotational temperatures and airglow emission rates. Figure 8 shows examples of the fitting of the synthetic spectra to the observed fringes shown in Fig. 7. The images in Fig. 7 are averaged over the azimuthal direction. The thick and thin curves are the observed and the fitted spectra, respectively. Crosses and vertical dashed lines indicate the data points and the range, respectively, which are used for the spectral fitting.

For $\mathrm{OH}(6,2)$ emissions in channels 1 and 2, we fit the synthetic spectra for the two ranges, including the $\mathrm{P}_{1}(2)$ (near pixel 50) and $\mathrm{P}_{1}(4)$ (near pixel 16) peaks, and do not use the peak at $\mathrm{P}_{1}(3)$ (near pixel 38). This is because the $\mathrm{P}_{1}(3)$ line is contaminated by other airglow emissions (e.g., Greet et al., 1998). For $\mathrm{O}_{2}(0,1)$ emissions in channels 3 and 4, we take the fitting range where the emission lines are bunched together between the lines of 865.91 and $867.07 \mathrm{~nm}$. The two major oxygen emissions in channels 5 $(557.7 \mathrm{~nm})$ and $6(630.0 \mathrm{~nm})$ are clearly fitted, while the third oxygen emission in channel 7 at $777.4 \mathrm{~nm}$ is very weak and significantly contaminated by the three airglow lines in the $\mathrm{OH}(9,4) Q$-branches $(\mathrm{Q} 1(1), \mathrm{Q}(2)$ and $\mathrm{Q}(3))$. The sodium $\mathrm{D}$ emissions in channel 8 are also very weak on this night. Since Platteville is at midlatitude, we cannot expect the $\mathrm{N}_{2}^{+}(1 \mathrm{NG})$ auroral emission at $427.8 \mathrm{~nm}$ in channel 9, while a weak emission is identified in the Hydrogen Balmer $\beta$ in channel 10. For $\mathrm{OH}(7,3) R$-branches in chan- 


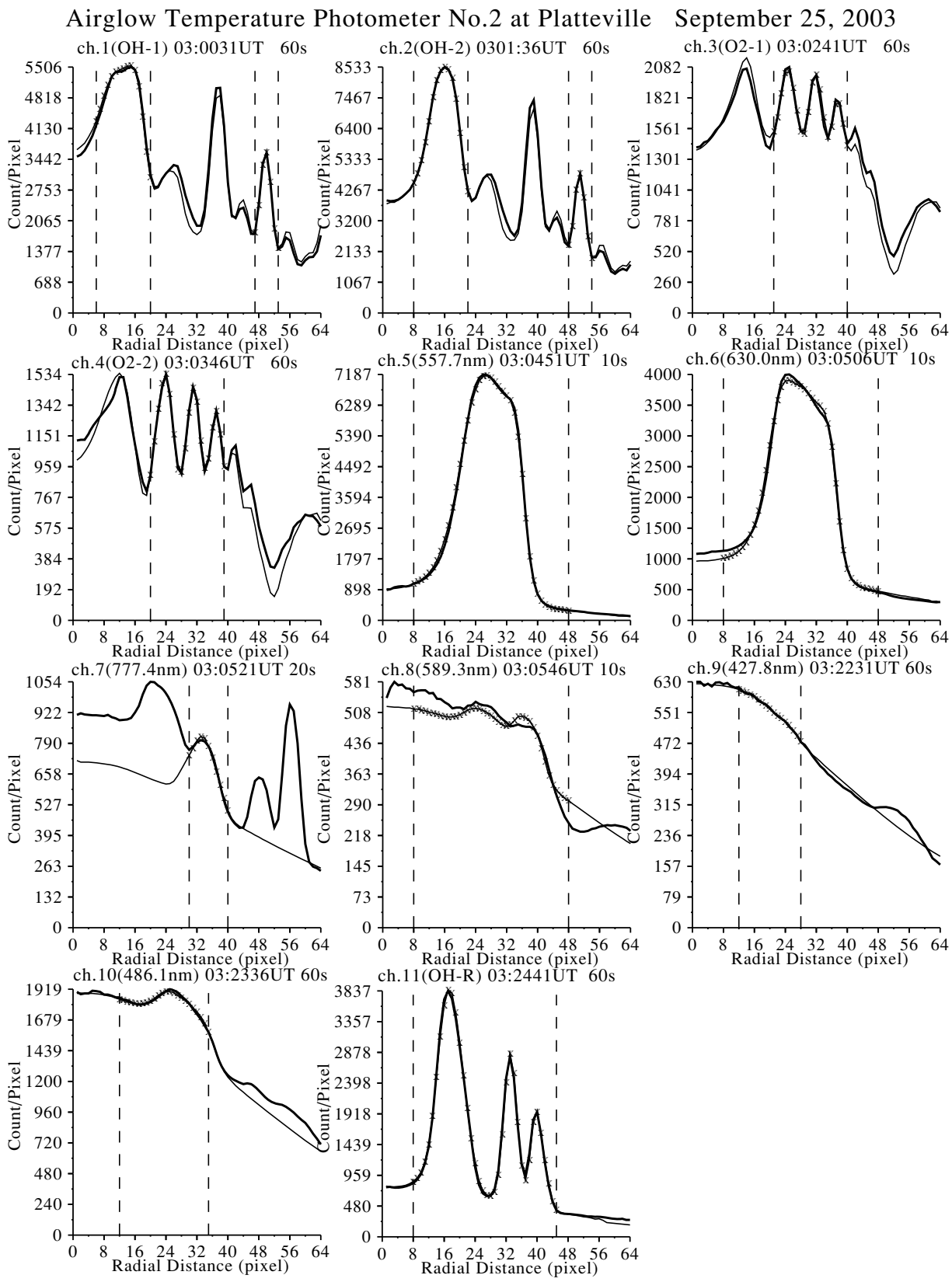

Fig. 8. Cross sections of the interference fringes shown in Fig. 7 (thick curves) and fitted synthetic spectra (thin curves). The images in Fig. 7 are averaged over the azimuthal direction, similarly to that of Figs. 3-6. Crosses and vertical dashed lines in each panel indicate the data points used for the spectral fitting.

nel 11 of Photometer 1, we fit the synthetic spectra to the whole range of the three lines.

Figures 9 and 10 indicate the nocturnal variations of airglow emission rates $I_{r}(\mathrm{R})$ and rotational temperatures $T$ (K) of $\mathrm{OH}$ (solid curves) and $\mathrm{O}_{2}$ (dashed curves) emissions obtained by the three photometers at Platteville on September 25 and 29, 2003, respectively. The background continuum intensity $I_{b}(\mathrm{R} / \mathrm{nm})$, fitting error (\% of maximum count) averaged for all the fitted pixels, and wavelength shift due to the variation of the filter temperature are also shown. Since the three photometers have two filters each for $\mathrm{OH}$ and $\mathrm{O}_{2}$ emissions, six solid and dashed curves are overplotted in this figure. The parameters obtained by the $\mathrm{OH}(7,3) R$-branch filter of Photometer 1 are indicated by small crosses.
The six filters of $\mathrm{OH}$ and $\mathrm{O}_{2}$ emissions give similar airglow emission rates in Figs. 9(e) and 10(e) with a difference of less than $\sim 20 \mathrm{R}$. The differences in temperature are mostly less than $10 \mathrm{~K}$, while channels $1(\mathrm{OH})$ and $3\left(\mathrm{O}_{2}\right)$ of Photometer 1 give systematically higher temperatures for both nights, with a difference of $\sim 15-20 \mathrm{~K}$, compared with the temperatures from other filters. The $\mathrm{O}_{2}$ temperature significantly increases at dawn because of the contamination of twilight. We continue the observation in the twilight until the zenith angle of the Sun becomes larger than $-12^{\circ}$.

The fitting errors in Figs. 9(b) and 10(b) are the average difference between the observed and synthetic spectra (in percentage) compared with the peak counts of the fringes and are mostly less than $1 \%$, indicating that the fitting of the synthetic spectra goes well. The wavelength shift due to 


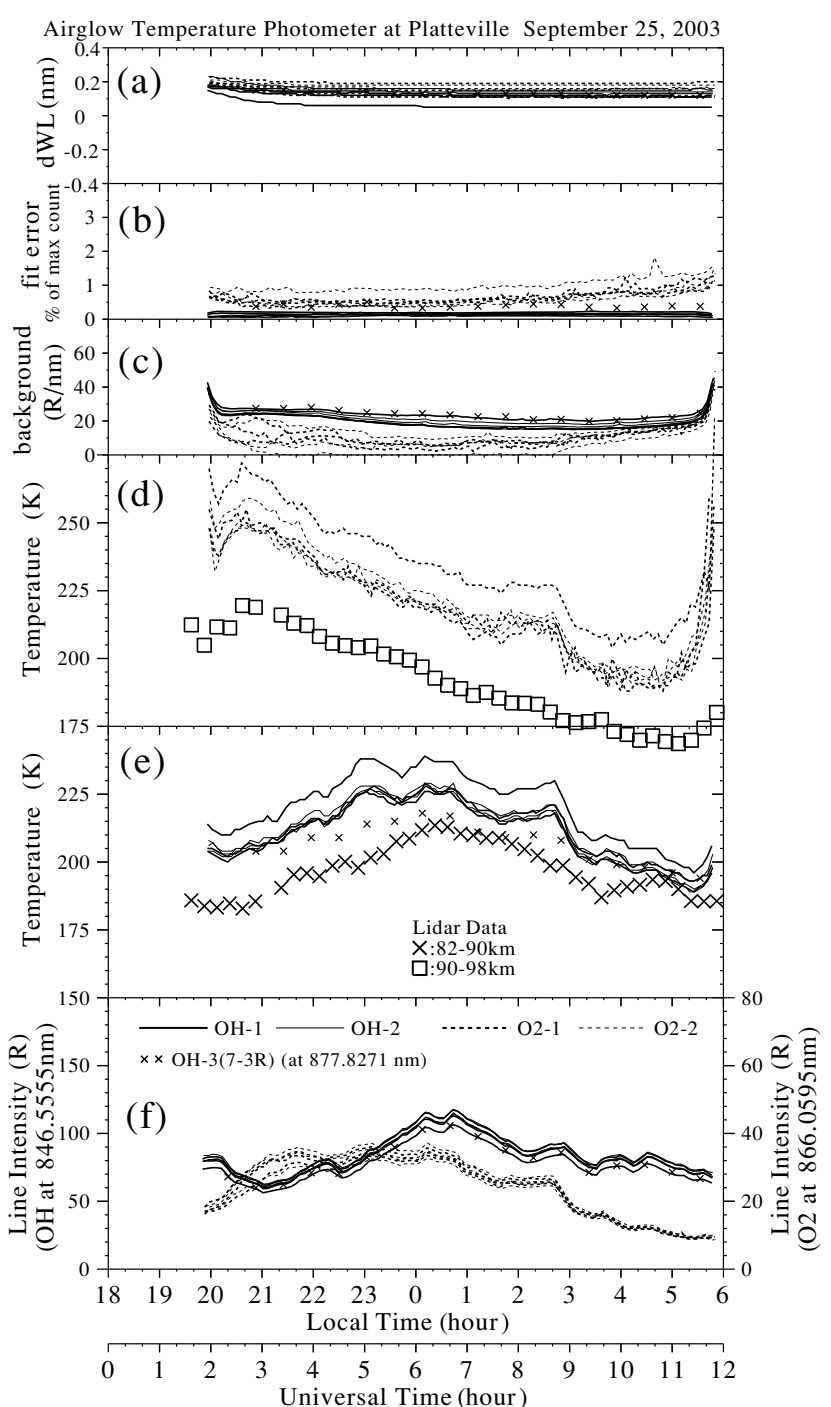

Fig. 9. From top to bottom: (a) wavelength shifts for fitting, (b) average fitting errors (in \%) from the maximum count, (c) background intensities, (d) and (e) rotational temperatures, and (f) line intensities, measured by the three airglow temperature photometers at Platteville, Colorado, on September 25, 2003. Six curves are overplotted for $\mathrm{OH}$ and $\mathrm{O}_{2}$, since the three photometers have two each filters for both the $\mathrm{OH}$ and $\mathrm{O}_{2}$ measurements. The parameters obtained by the $\mathrm{OH}(7,3) R$-branch filter of Photometer 1 are indicated by small crosses. The crosses and squares indicate temperatures obtained by a sodium lidar at Fort Collins, Colorado and are averaged over 82-90 km and 90-98 km, respectively.

the filter temperature variation in Figs. 9(a) and 10(a) ranges between 0.0 and $0.2 \mathrm{~nm}$, suggesting that the temperatures of the filter during the observation are $\sim 0-10^{\circ} \mathrm{C}$ higher than those at the calibration. The large crosses and squares in Figs. 9(d), 9(e), 10(d), and 10(e) indicate the temperatures obtained by a sodium lidar, which we discuss in the next section.

Figures 11 and 12 show airglow emission rates at wavelengths of 557.7, 630.0, 777.4, 589.3, 427.8, and $486.1 \mathrm{~nm}$ (channels 5-10), as well as the background continuum intensities and fitting errors obtained by the three photometers at Platteville on September 25 and 29, 2003, respectively. Three curves are overplotted for each airglow line. The three photometers give fairly consistent intensities for these emissions for both nights. The sodium emission inten-

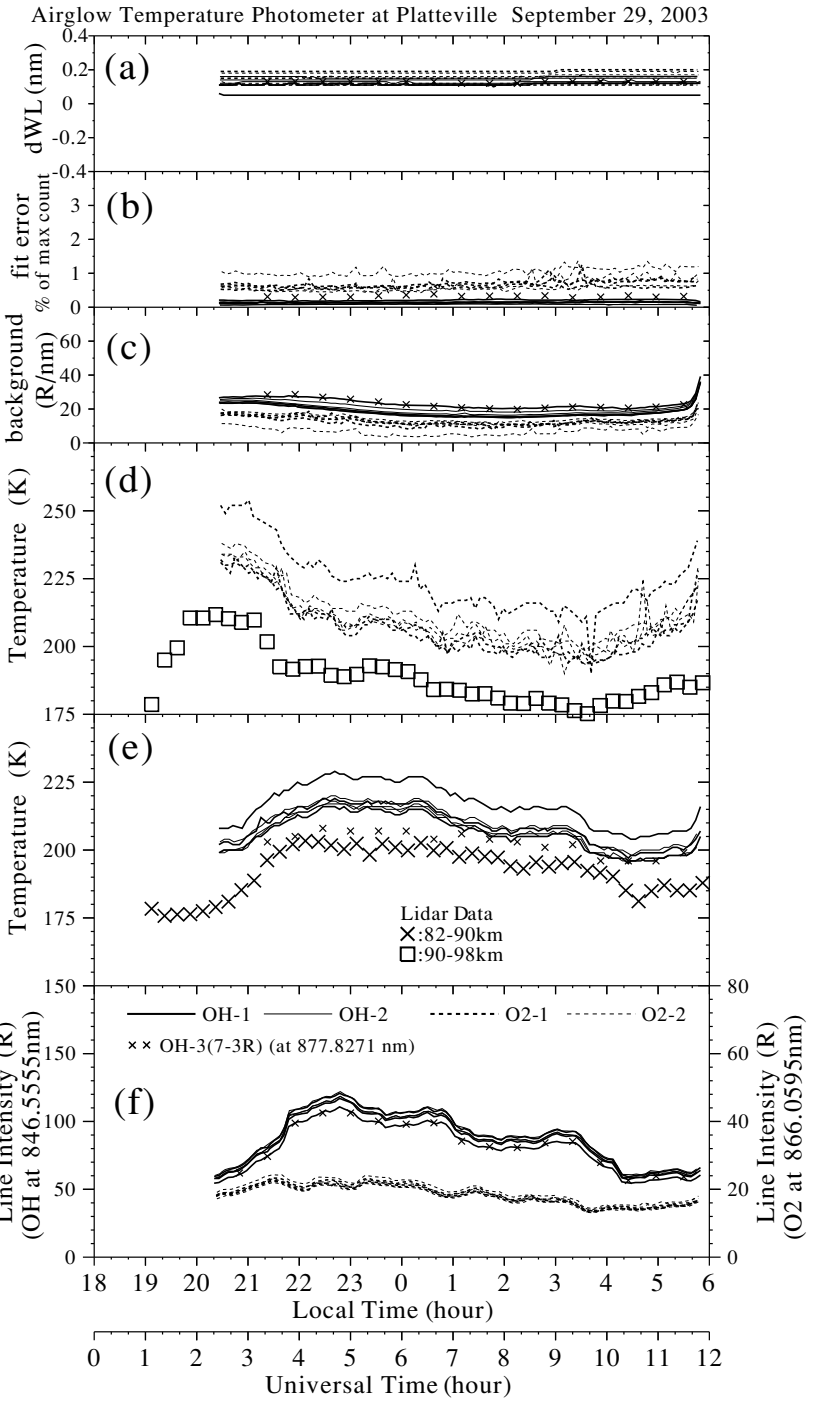

Fig. 10. From top to bottom: (a) wavelength shifts, (b) average fitting errors, (c) background intensities, (d) and (e) rotational temperatures, and (f) line intensities, measured by the three airglow temperature photometers at Platteville, Colorado, on September 29, 2003, in the same format as that in Fig. 9.

sity at $589.3 \mathrm{~nm}$ shows a slight difference of $\sim 5 \mathrm{R}$ between the photometers. The fitting errors in the top panels are also highest for the sodium emission in two photometers. For auroral lines at 427.8 and $486.1 \mathrm{~nm}$, the noise level of the photometers is very low, indicating that the photometers can measure weak emissions associated with energetic particle precipitation from ring current during magnetic storms at midlatitudes (e.g., Tinsley et al., 1984). The 486.1-nm emission in the evening of both nights may correspond to the geocorona.

\section{Comparison with a Sodium Lidar}

Sodium lidar can measure the absolute value of the temperature in the middle atmosphere. It gives accurate absolute temperatures with a typical measurement precision of $\sim 0.6 \mathrm{~K}$ and $\sim 5 \mathrm{~K}$ near the peak $(92 \mathrm{~km})$ and edges (81 and $107 \mathrm{~km}$ ) of the sodium layer (She et al., 2000). The location of our test measurement, Platteville, was selected to make a comparison with the sodium lidar operated by the Colorado 


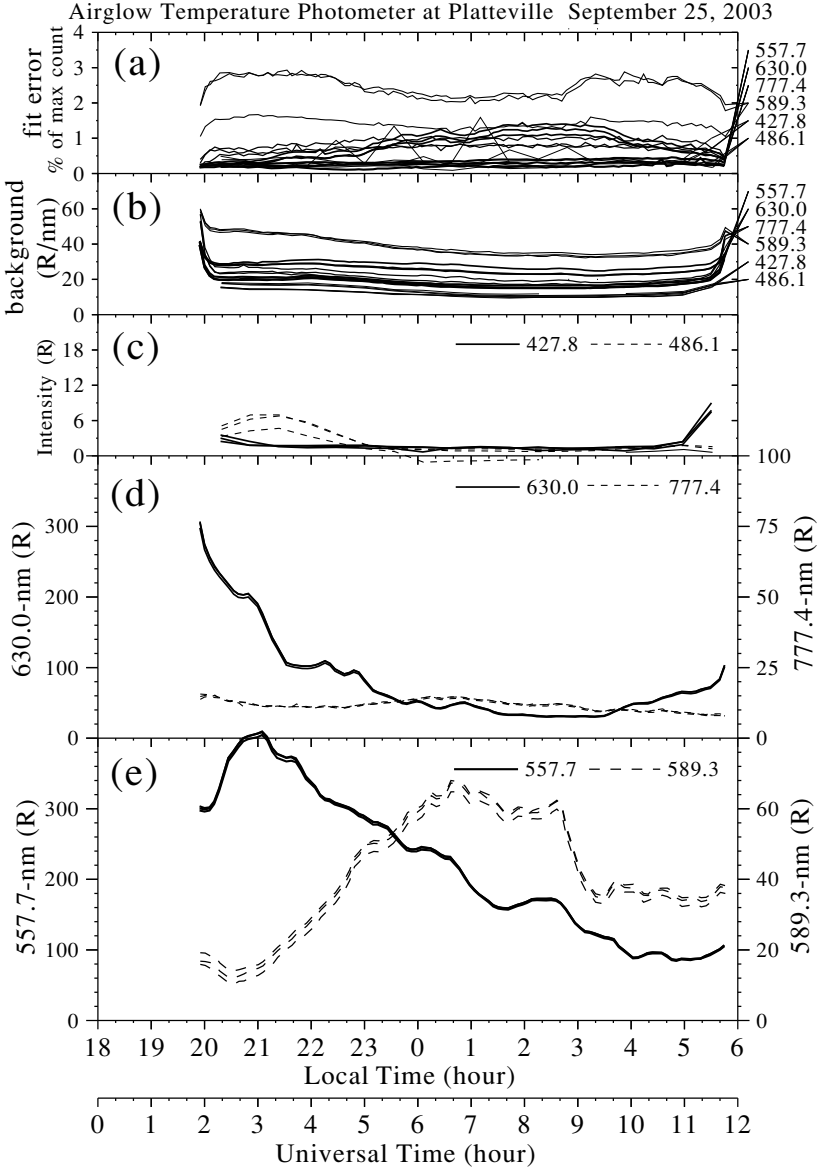

Fig. 11. From top to bottom: (a) average fitting errors (in \%) from the maximum count, (b) background intensities, (c) intensities at wavelengths of 427.8 and $486.1 \mathrm{~nm}$, (d) intensities at wavelengths of 630.0 and $777.4 \mathrm{~nm}$, and (e) intensities at 557.7 and $589.3 \mathrm{~nm}$, measured by the three airglow temperature photometers at Platteville, Colorado, on September 25, 2003. Three curves are overplotted for all the parameters.

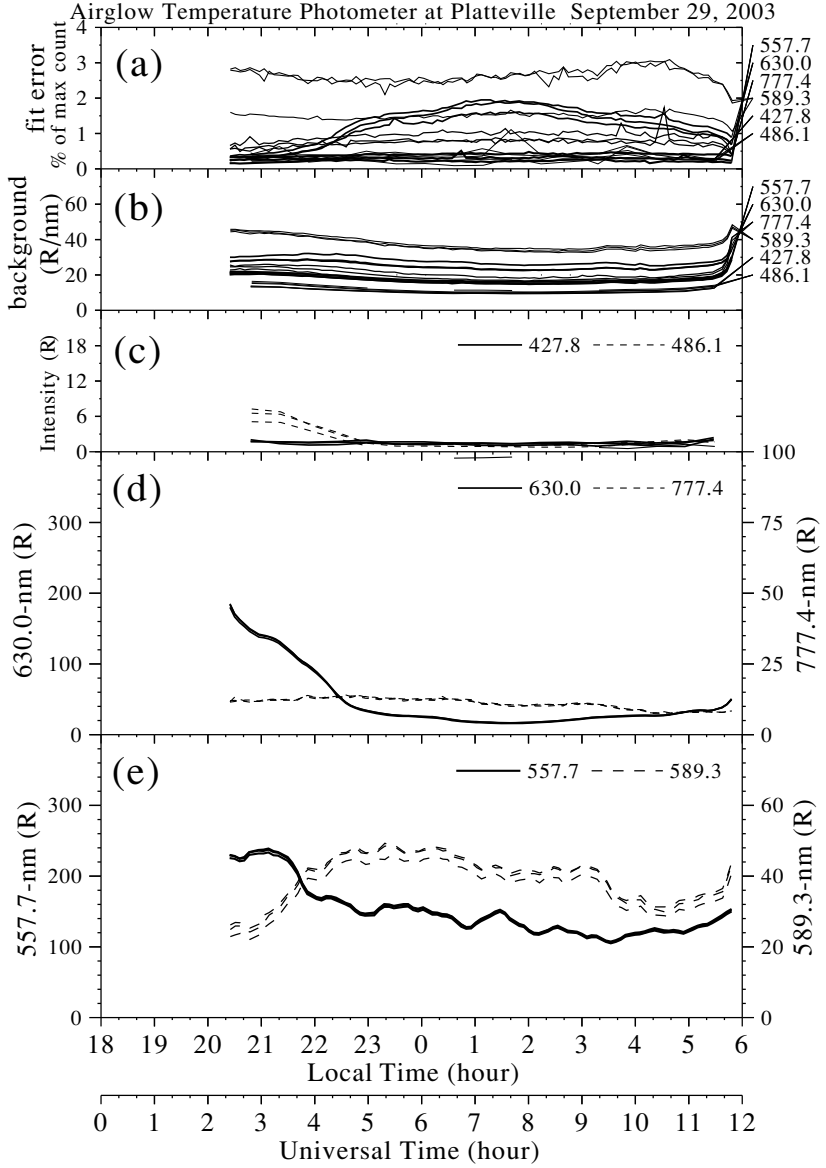

Fig. 12. From top to bottom: (a) average fitting errors (in \%) from the maximum count, (b) background intensities, (c) intensities at wavelengths of 427.8 and $486.1 \mathrm{~nm}$, (d) intensities at wavelengths of 630.0 and $777.4 \mathrm{~nm}$, and (e) intensities at 557.7 and $589.3 \mathrm{~nm}$, measured by the three airglow temperature photometers at Platteville, Colorado, on September 29, 2003, in the same format as that in Fig. 11.
State University (CSU) at Fort Collins $\left(40.6^{\circ} \mathrm{N}, 254.9^{\circ} \mathrm{E}\right)$, Colorado. The sodium lidar is located $\sim 60 \mathrm{~km}$ northwest of Platteville. The lidar has a northward and an eastward beam, which crosses the mesopause region about $100 \mathrm{~km}$ NNW and $50 \mathrm{~km}$ NNE from Platteville, respectively. The field-of-view $\left(16^{\circ}\right)$ of the photometers corresponds to a circular area with a diameter of $\sim 50 \mathrm{~km}$ at the altitudes of the $\mathrm{OH}$ and $\mathrm{O}_{2}$ airglow layers. The relative locations of Platteville, CSU, and the lidar beams were shown by She et al. (2004). Several researchers have used the mesospheric temperature data from the CSU lidar for comparison with the temperatures from airglow photometers and spectrometers (e.g., She and Lowe, 1998; Melo et al., 2001; Taylor et al., 2001).

The large crosses and squares in Figs. 9(d), 9(e), 10(d), and 10(e) indicate temperatures obtained by the CSU sodium lidar with a time resolution of $15 \mathrm{~min}$. The temperatures are averaged for the two beams and altitude ranges of 82-90 km and 90-98 km, which correspond to the typical airglow layers of $\mathrm{OH}$ and $\mathrm{O}_{2}$ emissions, respectively. The variations of the rotational temperatures obtained by the photometers are similar to the variations of the lidar temperatures. However, the absolute values of the photometer temperatures are systematically higher than the lidar tem- peratures with differences of 20-30 K for both $\mathrm{OH}$ and $\mathrm{O}_{2}$ emissions for both nights.

To investigate the temperature difference between the photometers and the lidar more systematically, we made a statistical comparison of the temperatures using eight nights (September 23 and 25-29 and October 1 and 5, 2003) of simultaneous observations by the photometers and the lidar. The results are shown in Fig. 13, which is the correlation of the temperatures obtained by the photometers and by the sodium lidar. The lidar temperatures are averaged over altitudes of 82-90 km for comparison with the $\mathrm{OH}$ temperatures and 90-98 km for comparison with the $\mathrm{O}_{2}$ temperatures. The solid lines indicate the linear regression lines of

$$
T_{\text {lidar }}(\mathrm{K})=a T_{\text {photometer }}(\mathrm{K})+b \text {. }
$$

For all 13 filters of the three photometers plotted in Fig. 13, the photometer temperatures are linearly correlated with the lidar temperature. The correlation coefficient $r$ is mostly larger than 0.8 except for channels 1 and 11 of Photometer $1(r \sim 0.7)$. The correlations for the $\mathrm{O}_{2}$ temperatures are generally better than those for the $\mathrm{OH}$ temperatures. The photometer temperatures are systematically lower than the lidar temperatures for all the channels. 

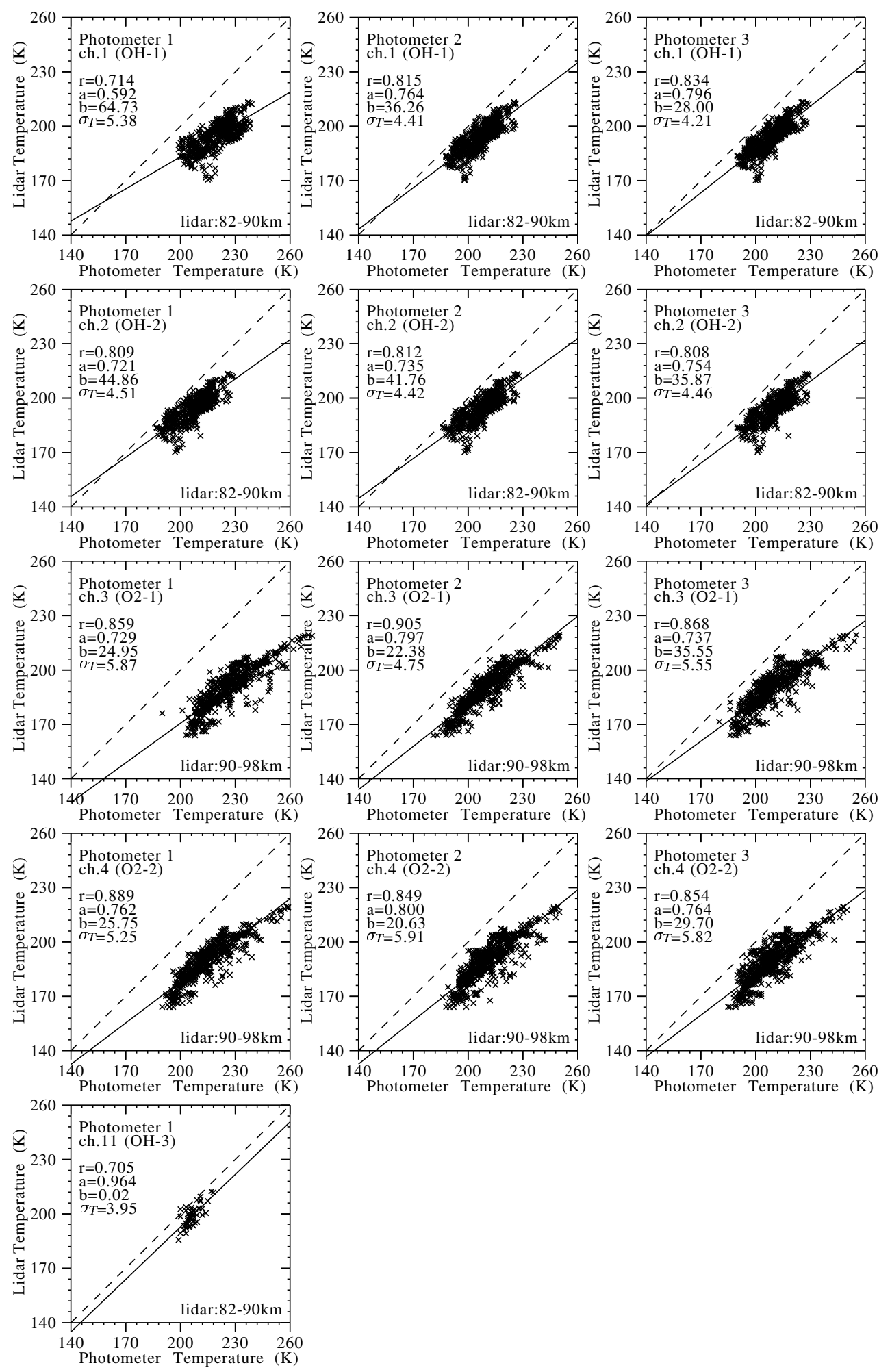

Fig. 13. Correlations of temperatures obtained by the three airglow temperature photometers at Platteville and by a sodium lidar at Fort Collins. The lidar temperatures are averaged over altitudes of $82-90 \mathrm{~km}$ for comparison with the $\mathrm{OH}$ temperatures and $90-98 \mathrm{~km}$ for comparison with the $\mathrm{O}_{2}$ temperatures. The solid lines are the linear fitting lines. $r, a, b$, and $\sigma_{T}$ are correlation coefficient, gradient and zero-crossing of the linear fitting lines, and standard deviation from the linear fitting lines, respectively.

The correlation coefficient $r$, gradient $a$, and zerocrossing $b(\mathrm{~K})$ of the linear fitting lines, and the standard deviation $\sigma_{T}(\mathrm{~K})$ from the linear fitting lines are listed in Table 2. The lidar temperatures are averaged over $\pm 4 \mathrm{~km}$ and $\pm 2 \mathrm{~km}$ from the typical altitudes of emission peak at 86 $\mathrm{km}$ for the $\mathrm{OH}$ emissions and $94 \mathrm{~km}$ for the $\mathrm{O}_{2}$ emissions.
The correlation coefficient $r$ is clearly larger for the lidar temperatures averaged over $\pm 4 \mathrm{~km}$ for all channels. The correlation coefficient $r$ for temperatures from the $\mathrm{OH}(7,3)$ $R$-branch (channel 11 of Photometer 1) is lower than those for temperatures from the $\mathrm{OH}(6,2) P$-branch (channels 1 and 2). As shown in the values of $\sigma_{T}$, we can convert the ro- 
Table 2. Correlations and linear fitting parameters of temperatures between the sodium lidar and the airglow temperature photometers. Better correlation is obtained for the lidar temperatures averaged over 82-90 $\mathrm{km}$ and $90-98 \mathrm{~km}$.

\begin{tabular}{|c|c|c|c|c|c|}
\hline Photometer & Channel & Correlation & $\mathrm{a}$ & $\begin{array}{c}\mathrm{b} \\
(\mathrm{K})\end{array}$ & $\begin{array}{c}\sigma_{T} \\
(\mathrm{~K})\end{array}$ \\
\hline \multicolumn{6}{|c|}{ Lidar altitude: $\mathrm{OH}: 82-90 \mathrm{~km}, \mathrm{O}_{2}: 90-98 \mathrm{~km}$} \\
\hline 1 & $1(\mathrm{OH}-1)$ & 0.714 & 0.592 & 64.7 & 5.4 \\
\hline 1 & $2(\mathrm{OH}-2)$ & 0.809 & 0.721 & 44.9 & 4.5 \\
\hline 1 & $3\left(\mathrm{O}_{2}-1\right)$ & 0.859 & 0.729 & 24.9 & 5.9 \\
\hline 1 & $4\left(\mathrm{O}_{2}-2\right)$ & 0.889 & 0.762 & 25.7 & 5.2 \\
\hline 1 & $11(\mathrm{OH}-3)$ & 0.705 & 0.964 & 0.0 & 3.9 \\
\hline 2 & $1(\mathrm{OH}-1)$ & 0.815 & 0.764 & 36.3 & 4.4 \\
\hline 2 & $2(\mathrm{OH}-2)$ & 0.812 & 0.735 & 41.8 & 4.4 \\
\hline 2 & $3\left(\mathrm{O}_{2}-1\right)$ & 0.905 & 0.797 & 22.4 & 4.8 \\
\hline 2 & $4\left(\mathrm{O}_{2}-2\right)$ & 0.849 & 0.800 & 20.6 & 5.9 \\
\hline 3 & $1(\mathrm{OH}-1)$ & 0.834 & 0.796 & 28.0 & 4.2 \\
\hline 3 & $2(\mathrm{OH}-2)$ & 0.808 & 0.754 & 35.9 & 4.5 \\
\hline 3 & $3\left(\mathrm{O}_{2}-1\right)$ & 0.868 & 0.737 & 35.5 & 5.6 \\
\hline 3 & $4\left(\mathrm{O}_{2}-2\right)$ & 0.854 & 0.764 & 29.7 & 5.8 \\
\hline \multicolumn{6}{|c|}{ Lidar altitude: $\mathrm{OH}: 84-88 \mathrm{~km}, \mathrm{O}_{2}: 92-96 \mathrm{~km}$} \\
\hline 1 & $1(\mathrm{OH}-1)$ & 0.636 & 0.630 & 56.1 & 7.1 \\
\hline 1 & $2(\mathrm{OH}-2)$ & 0.742 & 0.789 & 30.2 & 6.1 \\
\hline 1 & $3\left(\mathrm{O}_{2}-1\right)$ & 0.826 & 0.756 & 18.6 & 7.0 \\
\hline 1 & $4\left(\mathrm{O}_{2}-2\right)$ & 0.860 & 0.795 & 18.5 & 6.3 \\
\hline 1 & $11(\mathrm{OH}-3)$ & 0.685 & 1.271 & -63.5 & 5.5 \\
\hline 2 & $1(\mathrm{OH}-1)$ & 0.749 & 0.833 & 21.8 & 6.0 \\
\hline 2 & $2(\mathrm{OH}-2)$ & 0.749 & 0.805 & 27.1 & 6.0 \\
\hline 2 & $3\left(\mathrm{O}_{2}-1\right)$ & 0.872 & 0.829 & 15.6 & 5.9 \\
\hline 2 & $4\left(\mathrm{O}_{2}-2\right)$ & 0.819 & 0.832 & 13.6 & 6.9 \\
\hline 3 & $1(\mathrm{OH}-1)$ & 0.776 & 0.880 & 10.2 & 5.7 \\
\hline 3 & $2(\mathrm{OH}-2)$ & 0.748 & 0.830 & 19.9 & 6.0 \\
\hline 3 & $3\left(\mathrm{O}_{2}-1\right)$ & 0.845 & 0.774 & 27.6 & 6.5 \\
\hline 3 & $4\left(\mathrm{O}_{2}-2\right)$ & 0.824 & 0.795 & 23.1 & 6.8 \\
\hline
\end{tabular}

tational temperatures obtained by the photometers to the lidar temperatures using these parameters with Eq. (13) with standard deviations of 4-6 K.

In the above comparison with the lidar data, we simply averaged the lidar temperatures for the given altitude ranges. To obtain the altitude averages, we also tried to use a Gaussian weighting function for the given altitude ranges with standard deviations of the half width of the altitude ranges. The results were almost the same as those from the simple averages. The differences in temperatures in Figs. 9 and 10 were mostly less than $5 \mathrm{~K}$. The differences in correlation coefficients in Table 2 were less than 0.03 .

Figure 14 shows a comparison of the temperatures obtained by the photometers and the lidar. The photometer temperatures are corrected using Eq. (13) with the parameters listed in the upper part of Table 2 (average for $\pm 4 \mathrm{~km}$ ). All the temperatures in six curves and small crosses from the three photometers fit well with the lidar temperatures, which are indicated by large crosses and squares. The temperatures are temporally different at $02-03$ LT in Fig. 14(c) and at 20-21 LT, 01-02 LT, and 04-05 LT in Fig. 14(d). These differences may be because of the height variation of the airglow emissions associated with gravity waves. The

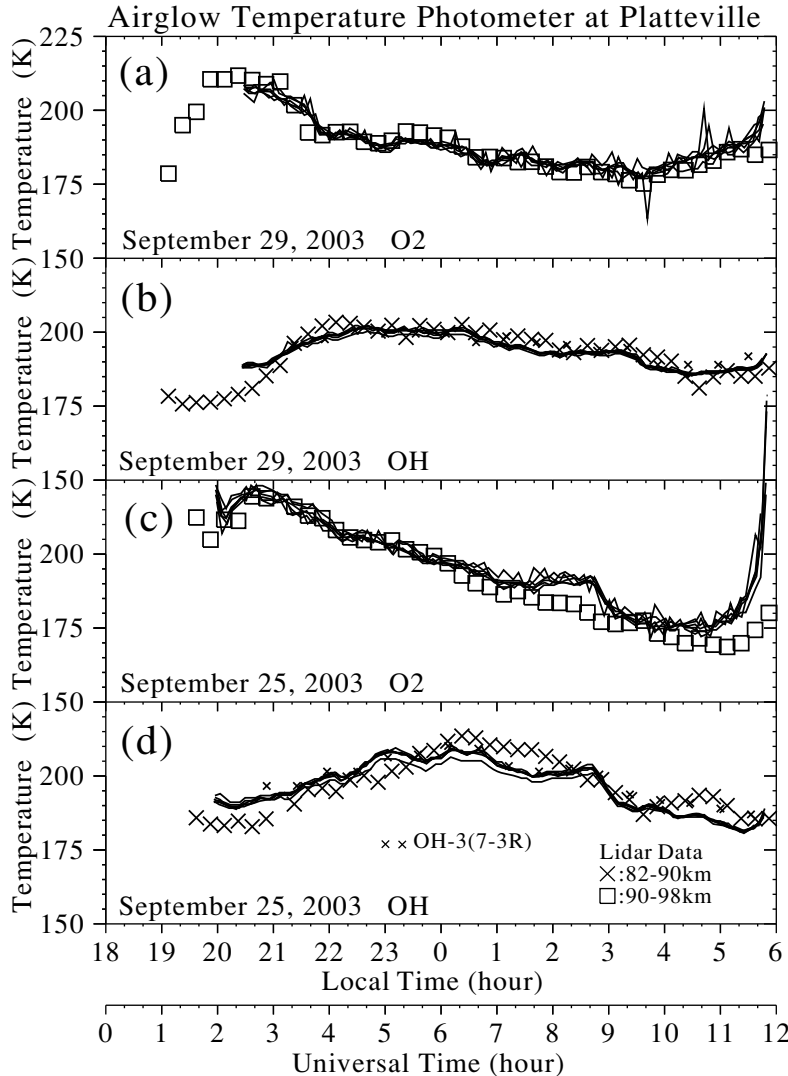

Fig. 14. Comparison of the temperatures obtained by the sodium lidar (squares and large crosses) and by the three airglow temperature photometers (solid curves and small crosses) for the nights of September 25 and 29,2003. The temperatures of the photometers are corrected by the linear fitting parameters listed in Fig. 13 and Table 2. Six solid curves are overplotted in each panel.

significant increase in photometer temperatures at 05-06 LT in Fig. 14(c) is because of contamination by twilight. We did not include the time interval of the twilight observations in the correlation analyses in Fig. 13 and Table 2.

\section{Discussion}

The absolute temperatures obtained by the three photometers are systematically higher than the temperatures obtained by the near-collocated sodium lidar, as shown in Figs. 9, 10, and 13. Here we discuss the possible causes of this temperature difference.

The temperature of the interference filter drifts according to the variations in the outside temperature. As a result, the interference fringes shift in radial direction. As discussed in data processing step (4) of Section 5, we correct this fringe drift by calculating the best-fit synthetic spectra. This correction may cause a systematic offset of the absolute temperature.

The drift of the fringe corresponds to a shift of less than $0.2 \mathrm{~nm}$ in wavelength range, as shown in Figs. 9(a) and 10(a). This wavelength shift of the filter causes a fringe shift of less than 1 pixel in radial distances. On the other hand, the transmission of the optics decreases with increasing radial distance, as shown in Figs. 3 and 4. This decrease is roughly about $1 \%$ per pixel. Thus, if we calibrate the wavelength shift of the filter incorrectly, it may cause a maxi- 
mum of a $1 \%$ difference in the estimation of peak intensity of airglow emission. For $\mathrm{OH}(6,2)$ rotational temperatures at $T=200 \mathrm{~K}$, the $1 \%$ difference of the peak intensity ratio of $\mathrm{P}_{1}(4) / \mathrm{P}_{1}(2)$ corresponds to the rotational temperature difference of only $\sim 2 \mathrm{~K}$. From these estimations, we conclude that the filter wavelength drift does not significantly affect the estimation of the absolute temperature. The average fitting errors shown in Figs. 9(b) and 10(b) are also less than $1 \%$, corresponding to a random error of rotational temperatures of less than $\sim 2 \mathrm{~K}$.

After the calibration of the photometers we noticed a possibility that the wavelength of the monochromatic calibration source, which is a grating spectrometer, might shift during the calibration due to a temperature change of the grating plate. Using another grating spectrometer, we found that the wavelength of the spectrometer shifted $\sim 0.3 \mathrm{~nm}$ during a few hours due to heat flux from the halogen lamp that was used as the light source. This shift can be monitored by using emission lines from a mercury lamp. However, we did not know how much the wavelength of the spectrometer was shifted during the calibration of the photometers, since we did not conduct frequent calibration of spectrometer wavelengths during the calibration of the photometers. Thus, we made a model calculation for those cases where the wavelength of the spectrometer shifts \pm 0.5 $\mathrm{nm}$ from the used values. The differences of the output temperatures between the non-shifted and shifted calibration data for the data of September 25, 2003 were less than $2 \mathrm{~K}$ for both $\mathrm{OH}$ and $\mathrm{O}_{2}$ temperatures, except for the cases that the fitting failed because of too much shift. Thus, we conclude that the wavelength shift of the grating spectrometer used for the calibration does not cause a significant error to the output temperatures.

Osterbrock et al. (2000) have shown high-resolution airglow spectra obtained by the Keck astronomical facility at Mauna Kea, Hawaii. The wavelengths of $\mathrm{OH}$ and $\mathrm{O}_{2}$ emission lines in their high-resolution spectra are slightly different from the theoretical spectra used in the present study (Fig. 1) and are in order of $0.01 \mathrm{~nm}$. Thus, considering the above analysis of the possible wavelength shift of the filter and the grating spectrometer, this inaccuracy of the wavelengths of airglow lines would also not cause significant errors in the output temperatures.

The transition probabilities which are used to calculate the rotational temperatures from the observed intensity ratio of rotational lines contain some ambiguity. Greet et al. (1998) showed in their Table 2 that the temperature corrections using the transition probabilities of Langhoff et al. (1986) (used in this paper) is $-14 \mathrm{~K}$ for the $\mathrm{OH}(6,2)$ $\mathrm{P}_{1}(2) / \mathrm{P}_{1}(4)$ ratio. French et al. (2000) estimated the differences in $\mathrm{OH}$ rotational temperatures to be $\sim 11 \mathrm{~K}$ for three transition probabilities by Mies (1974), Langhoff et al. (1986), and Turnbull and Lowe (1989), respectively.

The other possible reason for the high rotational temperatures compared with the lidar temperatures is the assumption of thermodynamic equilibrium for the rotational levels. Pendleton et al. (1993) have shown that for high rotational quantum numbers, the $\mathrm{OH}$ rotational populations can strongly deviate from the thermodynamic equilibrium values. If the rotational levels are not in thermodynamic equi- librium, the estimated temperature would become higher than the atmospheric temperature.

Despite the large difference in absolute temperatures, the linear regression parameters listed in Table 2 (averaged over 82-90 km and 90-98 km) correct the photometer temperatures to the lidar temperature very well, with differences of 4-6 K in standard deviation. This difference is possibly because of the height variation of the airglow layers. The peak height of the airglow layers can vary a few kilometers over time because of gravity waves and tides (e.g., Zhang et al., 1993; Zhang and Shepherd, 1999; Fujii et al., 2004). It should be noted that Zhao et al. (2005) have made a similar comparison of lidar and photometer temperatures using data collected during 16 nights at Hawaii $\left(20.8^{\circ} \mathrm{N}\right.$, $\left.156.2^{\circ} \mathrm{W}\right)$. They found that the tides or long-period gravity waves can cause a systematic decrease in the altitudes of both $\mathrm{OH}$ and $\mathrm{O}_{2}$ emission layers by up to several kilometers. This effect caused differences of temperature up to $\sim 10 \mathrm{~K}$ in their comparison. The linear regression lines obtained by the present analysis should contain ambiguities due to this effect of tidal forcing to the airglow layer height.

\section{Concluding Remarks}

In this paper, we report in detail the optical configuration, calibration, and data processing of the three airglow temperature photometers as well as a comparison with the CSU lidar. Although the rotational temperature measurement contains several assumptions of airglow layer height, transition probabilities, and thermodynamic equilibrium, it is still useful to monitor the mesospheric temperature because the photometer is a compact instrument and easily automated. This advantage of the photometer makes it suitable for network measurement of the mesospheric temperatures at multiple stations. The good temperature correlation among the 13 filters of the three photometers and between the photometers and the lidar guarantees such a network measurement. The three photometers are currently in operation at Rikubetsu $\left(43.5^{\circ} \mathrm{N}, 143.8^{\circ} \mathrm{E}\right)$, Sata $\left(31.0^{\circ} \mathrm{N}, 130.7^{\circ} \mathrm{E}\right)$, Japan, and Kototabang, Indonesia $\left(0.2^{\circ} \mathrm{S}, 100.3^{\circ} \mathrm{E}\right)$ to monitor latitudinal difference of global-scale waves in the mesosphere. The present result also indicates that the cross calibration is essentially important for the network measurement of rotational temperatures.

Acknowledgments. The calibration of the photometers was carried out using the optical facilities of the National Institute of Polar Research (NIPR), Japan. We thank S. Takeshita for his kind support of the calibration at NIPR. The work at Colorado State University was supported by NSF grant ATM-00-03171 and NASA grant NAG5-10076. S. Suzuki was supported by a Grant-in-Aid for JSPS Fellows (17-7673) of the Ministry of Education, Culture, Sports, Science and Technology of Japan. This work was supported by Grant-in-Aid for Scientific Research (13573006 and 18403011) and on Priority Area-764 (13136201) of the Ministry of Education, Culture, Sports, Science and Technology of Japan, and partly by the 21 st Century COE Program "Dynamics of the Sun-Earth-Life Interactive System (SELIS)" of Nagoya University, Japan.

\section{References}

Chamberlain, J., Physics of the aurora and airglow, Academic Press, New York, 1961.

Cho, Y.-M. and G. G. Shepherd, Correlation of airglow temperature and 
emission rate at Resolute Bay $\left(74.68^{\circ} \mathrm{N}\right)$, over four winters (20012005), Geophys. Res. Lett., 33, L06815, doi:10.1029/2005GL025298, 2006.

Cho, Y.-M., G. G. Shepherd, Y.-I. Won, S. Sargoytchev, S. Brown, and B. Solheim, MLT cooling during stratospheric warming events, Geophys. Res. Lett., 31, L10104, doi:10.1029/2004GL019552, 2004.

Coxon, J. A. and S. C. Foster, Rotational analyses of hydroxyl vibrationrotation emission bands: Molecular constants for $\mathrm{OH} \mathrm{X}^{2} \pi(6<v<$ 10), Can. J. Phys., 60, 41-48, 1982.

French, W. J. R., G. B. Burns, K. Finlayson, P. A. Greet, R. P. Lowe, and P. F. B. Williams, Hydroxyl $(6,2)$ airglow emission intensity ratios for rotational temperature determination, Ann. Geophys., 18, 1293-1303, 2000.

Fujii, J., T. Nakamura, T. Tsuda, and K. Shiokawa, Comparison of winds measured by MU radar and Fabry-Perot interferometer and effect of OI5577 airglow height variations, J. Atmos. Solar-Terr. Phys., 66, 573583, 2004.

Gavrilyeva, G. A. and P. P. Ammosov, Near-mesopause temperatures registered over Yakutia, Journal of Atmos. Solar-Terr. Phys., 64 985-990, 2002.

Greet, P. A., W. J. R. French, G. B. Burns, P. F. B. Williams, R. P. Lowe, and K. Finlayson, $\mathrm{OH}(6-2)$ spectra and rotational temperature measurements at Davis, Antarctica, Ann. Geophys., 16, 77-89, 1998.

Krupenie, P. H., The spectrum of molecular oxygen, J. Phys. Chem., ref. data 1: 423-487, 1972.

Langhoff, S. R., H.-J. Werner, and P. Rosmus, Theoretical transition for the OH Meinel system, J. Mol. Spectrosc., 118, 507-529, 1986.

López-González, M. J., E. Rodríguez, R. H. Wiens, G. G. Shepherd, S. Sargoytchev, S. Brown, M. G. Shepherd, V. M. Aushev, J. J. López-Moreno, R. Rodrigo, and Y.-M. Cho, Seasonal variations of $\mathrm{O}_{2}$ atmospheric and $\mathrm{OH}(6-2)$ airglow and temperature at mid-latitudes from SATI observations, Ann. Geophys, 22, 819-828, 2004.

Meinel, A. B., $\mathrm{O}_{2}$ emission bands in the infrared spectrum of the night sky, Astrophys. J., 112, 464-468, 1950.

Melo, S. M. L., R. P. Lowe, W. R. Pendleton, M. J. Taylor, B. P. Williams, and C. Y. She, Effects of a large mesospheric temperature enhancement on the hydroxyl rotational temperature as observed from the ground, $J$. Geophys. Res., 106, 30,381-30,388, 2001

Meriwether, J. W., High-latitude airglow observations of correlated shortterm fluctuations in the Hydroxyl Meinel 8-3 band intensity and rotational temperature, Planet. Space Sci., 23, 1211-1221, 1975.

Mies, F. H., Calculated vibrational transition probabilities of $\mathrm{OH}(\mathrm{X} 2 \mathrm{II}), J$. Mol. Spectr., 53, 150-188, 1974.

Osterbrock, D. E., R. T. Waters, and T. A. Barlow, Faint emission lines in the blue and red spectral regions of the night airglow, Publ. Astron. Soc. Pacific, 112, 733-741, 2000; http://crvax.sri. com/NVAO/download/Osterbrock.html.

Pendleton, W. R., Jr. and M. J. Taylor, The impact of $L$-uncoupling on Einstein coefficients for the $\mathrm{OH}$ Meinel $(6,2)$ band: Implications for $Q$ branch rotational temperatures, J. Atmos. Solar-Terr. Phys., 64, 971983, 2002.

Pendleton, W. R., P. J. Epsy, and M. R. Hammond, Evidence for nonlocal-thermodynamic-equilibrium rotation in the $\mathrm{OH}$ nightglow, J. Geophys. Res., 98, 11,567-11,579, 1993.

Sargoytchev, S. I., S. Brown, B. H. Solheim, Y.-M. Cho, G. G. Shepherd, and M. J. López-González, Spectral airglow temperature imager (SATI): a ground-based instrument for the monitoring of mesosphere temperature, Appl. Opt., 43, No. 30, 5712-5721, 2004.

She, C. Y. and R. P. Lowe, Seasonal temperature variations in the mesopause region at mid-latitude: Comparison of lidar and hydroxyl rotational temperatures using WINDII/UARS OH Height profiles, J. Atmos. Solar-Terr. Phys., 60, 1573-1583, 1998.

She, C. Y., S. Chen, Z. Hu, J. Sherman, J. D. Vance, V. Vasoli, M. A. White, J. Yu, and D. A. Krueger, Eight-year climatology of nocturnal temperature and sodium density in the mesopause region (80 to $105 \mathrm{~km})$ over Fort Collins, $\mathrm{CO}\left(41^{\circ} \mathrm{N}, 105^{\circ} \mathrm{W}\right)$, Geophys. Res. Lett., 27, 3289 3292, 2000.

She, C. Y., T. Li, B. P. Williams, T. Yuan, and R. H. Picard, Concurrent OH imager and sodium temperature/wind lidar observation of a mesopause region undular bore event over Fort Collins/Platteville, Colorado, $J$. Geophys. Res., 109, D22107, doi:10.1029/2004JD004742, 2004.

Shiokawa, K., Y. Otsuka, T. Ogawa, H. Takahashi, T. Nakamura, and T. Shimomai, Comparison of $\mathrm{OH}$ rotational temperatures measured by the Spectral Airglow Temperature Imager (SATI) and by a tilting-filter photometer, J. Atmos. Solar-Terr. Phys., 66, 891-897, 2004.

Sigernes, F., N. Shumilov, C. S. Deehr, K. P. Nielsen, T. Svenoe, and O. Havnes, Hydroxyl rotational temperature record from the auroral station in Adventdalen, Svalbard $\left(78^{\circ} \mathrm{N}, 15^{\circ} \mathrm{E}\right), J$. Geophys. Res., 108(A9), 1342, doi:10.1029/2001JA009023, 2003.

Slanger, T. G., P. C. Cosby, and D. L. Huestis, Ground-based observation of high-altitude, high-temperature emission in the $\mathrm{O} 2$ atmospheric band nightglow, J. Geophys. Res., 108(A7), 1293, doi: 10.1029/2003JA009885, 2003.

Takahashi, H., T. Nakamura, T. Tsuda, R. A. Buriti, and D. Gobbi, First measurement of atmospheric density and pressure by meteor diffusion coefficient and airglow $\mathrm{OH}$ temperature in the mesopause region, Geophys. Res. Lett., 29(8), 1165, doi:10.1029/2001GL014101, 2002.

Taori, A., M. J. Taylor, and S. Franke, Terdiurnal wave signatures in the upper mesospheric temperature and their association with the wind fields at low latitudes $\left(20^{\circ} \mathrm{N}\right), J$. Geophys. Res., 110, D09S06, doi:10.1029/2004JD004564, 2005.

Taylor, M. J., Jr., H.-L. Liu, C. Y. She, L. C. Gardner, R. G. Roble, and V. Vasoli, Large amplitude perturbations in mesospheric $\mathrm{OH}$ Meinel and $87-\mathrm{km} \mathrm{Na}$ lidar temperatures around the autumnal equinox, Geophys. Res. Lett., 28(9), 1899-1902, 2001.

Tinsley, B. A., R. P. Rohrbaugh, H. Rassoul, E. S. Barker, A. L. Cochran, W. D. Cochran, B. J. Wills, D. W. Wills, and D. Slater, Spectral characteristics of two types of low latitude aurorae, Geophys. Res. Lett., 11, $572-575,1984$.

Turnbull, D. N. and R. P. Lowe, New hydroxyl transition probabilities and their importance in airglow studies, Planet. Space Sci., 37(6), 723-738, 1989.

Wiens, R. H., S.-P. Zhang, R. N. Peterson, and G. G. Shepherd, MORTI: A mesopause oxygen rotational temperature imager, Planet. Space Sci., 39, 1363-1375, 1991 .

Wiens, R. H., A. Moise, S. Brown, S. Sargoytchev, R. N. Peterson, G. G. Shepherd, M. J. López-González, J. J. López-Moreno, and R. Rodrigo, SATI: A spectral airglow temperature imager, Adv. Space Res., 19, 677680, 1997.

Won, Y.-I., Q. Wu, Y. M. Cho, G. G. Shepherd, T. L. Killeen, P. J. Espy, Y. Kim, and B. Solheim, Polar cap observations of mesospheric and lower thermospheric 4-hour waves in temperature, Geophys. Res. Lett., 30(7), 1377, doi:10.1029/2002GL016364, 2003.

Zhang, S. P. and G. G. Shepherd, The influence of the diurnal tide on the $\mathrm{O}\left({ }^{1} \mathrm{~S}\right)$ and $\mathrm{OH}$ emission rates observed by WINDII on UARS, Geophys. Res. Lett., 26, 529-532, 1999.

Zhang, S. P., R. H. Wiens, and G. G. Shepherd, Gravity waves from $\mathrm{O}_{2}$ nightglow during the AIDA '89 campaign II: numerical modeling of the emission rate/temperature ratio, $\eta, J$. Atmos. Terr. Phys., 55, 377-395, 1993.

Zhao, Y., M. J. Taylor, and X. Chu, Comparison of simultaneous Na lidar and mesospheric nightglow temperature measurements and the effects of tides on the emission layer heights, J. Geophys. Res., 110, D09S07, doi:10.1029/2004JD005115, 2005

K. Shiokawa (e-mail: shiokawa@stelab.nagoya-u.ac.jp), Y. Otsuka, S. Suzuki, T. Katoh, Y. Katoh, M. Satoh, T. Ogawa, H. Takahashi, D. Gobbi, T. Nakamura, B. P. Williams, C.-Y. She, M. Taguchi, and T. Shimomai 